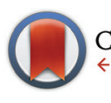

CrossMark

Cite this: Dalton Trans., 2015, 44 3092

Received 24th October 2014, Accepted 22nd December 2014 DOI: $10.1039 / c 4 d t 03279 a$

www.rsc.org/dalton

\title{
Synthesis of phosphinoferrocene amides and thioamides from carbamoyl chlorides and the structural chemistry of Group 11 metal complexes with these mixed-donor ligands $\uparrow$
}

Tiago A. Fernandes, ${ }^{a}$ Hana Solařová, ${ }^{a}$ Ivana Císařová, ${ }^{a}$ Filip Uhlík, ${ }^{b}$ Martin Štícha ${ }^{\mathrm{c}}$ and Petr Štěpnička*a

\begin{abstract}
The reaction of in situ generated 1'-(diphenylphosphino)-1-lithioferrocene with carbamoyl chlorides, ClC(E) $\mathrm{NMe}_{2}$, affords the corresponding (thio)amides, $\mathrm{Ph}_{2} \mathrm{PfCC}(\mathrm{E}) \mathrm{NMe}_{2}(\mathrm{E}=\mathrm{O}$ (2), S (3); fC = ferrocene-1,1'diyl). These compounds as well as their analogues, $\mathrm{Ph}_{2} \mathrm{PfcC}(\mathrm{O}) \mathrm{NHMe}(\mathbf{4})$ and $\mathrm{Ph}_{2} \mathrm{PfcC}(\mathrm{O}) \mathrm{NH}_{2}$ (5), prepared from 1'-(diphenylphosphino)ferrocene-1-carboxylic acid (Hdpf) were studied as ligands for the Group 11 metal ions. In the reactions with $\left[\mathrm{Cu}\left(\mathrm{MeCN}_{4}\right]\left[\mathrm{BF}_{4}\right]\right.$, the amides give rise to bis-chelate complexes of the type $\left[\mathrm{Cu}\left(\mathrm{L}-\mathrm{k}^{2} \mathrm{O}, \mathrm{P}\right)_{2}\right]\left[\mathrm{BF} \mathrm{F}_{4}\right]$. Similar products, $\left[\mathrm{Ag}\left(\mathrm{L}-\mathrm{k}^{2} \mathrm{O}, \mathrm{P}\right)_{2}\right] \mathrm{ClO}_{4}$, are obtained from silver(I) perchlorate and 2, 4 or $\mathbf{5}$. In contrast, the reaction of $\mathrm{AgClO}_{4}$ with 3 produces a unique molecular dimer $[\mathrm{Ag}(\mathbf{3})$ $\left.\left(\mathrm{ClO}_{4}-\mathrm{KO}\right)\right]_{2}$, where the metal centres are bridged by the sulfur atoms of the P,S-chelating thioamides. The reactions of 2-5 with [AuCl(tht)] (tht = tetrahydrothiophene) afford the expected gold(I)-phosphine complexes, $[\mathrm{AuCl}(\mathrm{L}-\mathrm{k} P)]$, containing uncoordinated (thio)amide moieties. Hemilabile coordination of the phosphinoamide ligands in complexes with the soft Group 11 metal ions is established by the crystal structure of a solvento complex, $\left[\mathrm{Cu}\left(5-\kappa^{2} O, P\right)(5-\kappa P)\left(\mathrm{CHCl}_{3}-\mathrm{kCl}\right)\right]\left[\mathrm{BF}_{4}\right]$, which was isolated serendipitously during an attempted crystallisation of $\left[\mathrm{Cu}\left(5-\mathrm{k}^{2} \mathrm{O}, P\right)_{2}\right]\left[\mathrm{BF}_{4}\right]$. All of the compounds are characterised by spectroscopic methods, and the structures of several representatives of both the free phosphinoamides and their complexes are determined by X-ray diffraction analysis and further studied by DFT calculations and cyclic voltammetry.
\end{abstract}

\section{Introduction}

Phosphine donors modified with carboxamide substituents have evolved into a specific class of functional phosphine ligands with applications in coordination and supramolecular chemistry, catalysis, biomedical research, etc. ${ }^{1,2}$ The attractiveness of these compounds lies mainly in their structural modu-

\footnotetext{
${ }^{a}$ Department of Inorganic Chemistry, Faculty of Science, Charles University in Prague, Hlavova 2030, 12840 Prague 2, Czech Republic. E-mail: stepnic@natur.cuni.cz

${ }^{b}$ Department of Physical and Macromolecular Chemistry, Faculty of Science, Charles University in Prague, Hlavova 2030, 12840 Prague 2, Czech Republic

${ }^{c}$ Department of Organic Chemistry, Faculty of Science, Charles University in Prague, Hlavova 2030, 12840 Prague 2, Czech Republic

$\dagger$ Electronic supplementary information (ESI) available: Summary of crystallographic parameters, an overlap of the two independent molecules in the structure of 8d, displacement ellipsoid plots for all structurally characterised compounds, comparison of the DFT optimised and experimental structures of 2 and 3, and DFT calculated coordinates for compounds 2, 3 and $\mathrm{FcC}(\mathrm{E}) \mathrm{NR}_{2}(\mathrm{E}=$ $\mathrm{O}, \mathrm{S} ; \mathrm{R}=\mathrm{H}, \mathrm{Me}$ ) as XYZ files. CCDC 1029509-1029520. For ESI and crystallographic data in CIF or other electronic format see DOI: 10.1039/c4dt03279a
}

larity and facile synthesis, especially via amide coupling reactions. ${ }^{1}$

During our studies ${ }^{3}$ on phosphinoferrocene carboxamides, we have also typically relied on the amide coupling reactions, ${ }^{4}$ employing 1 '-(diphenylphosphino)ferrocene-1-carboxylic acid (Hdpf), ${ }^{5}$ suitable functional amines and conventional peptide coupling agents (route A in Scheme 1). Although this synthetic strategy proved very efficient, we felt that the search for alternative synthetic routes that are more straightforward and avoid the use of expensive stoichiometric reagents was still desirable. Thus far, we have demonstrated that phosphinoferrocene carboxamides can be synthesised equally well by lithiation of $1^{\prime}$-(diphenylphosphino)-1-bromoferrocene $(\mathbf{1})^{6}$ and subsequent reaction of the lithiated intermediate with isocyanates (route $\mathrm{B}$ in Scheme 1). ${ }^{7}$

In an attempt to extend this preparative strategy, we decided to replace isocyanates with carbamoyl chlorides (route $\mathrm{C}$ in Scheme 1). ${ }^{8}$ Although the choice of substituents is inherently limited in carbamoyl halides because of their high reactivity, we reasoned that a reaction of lithiated intermediates with these reagents ${ }^{9}$ could possibly offer an alternative direct 
A
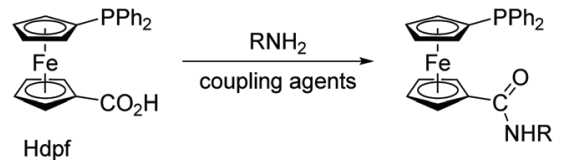

B Hdpf
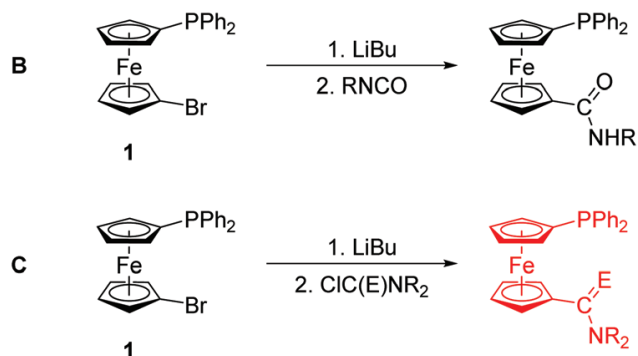

Scheme 1 Synthetic routes to phosphinoferrocene carboxamides: conventional amidation (A) and lithiation/electrophilic quenching ( $\mathrm{B}$ and $\mathrm{C} ; \mathrm{E}=\mathrm{O}$ and $\mathrm{S})$.

route to phosphinoamides and their corresponding thioamides that do not require protection of the already present phosphine moiety from an undesired oxidation. ${ }^{10}$ In this regard, a practical synthesis of phosphine-thioamides is particularly attractive as it may provide access to this type of mixed-donor ligands and thus initiate investigations into their coordination properties, which still remain largely unexplored. ${ }^{11}$ To the best of our knowledge, there is only one report on the synthesis of a phosphine-thioamide donor via the rather unconventional Diels-Alder $[4+2]$-cycloaddition of $\mathrm{N}, \mathrm{N}$-dimethylthioacrylamide across 3,4-dimethyl-1-phenyl-1 $\mathrm{H}$ phosphole bonded to a $\operatorname{Pd}(\mathrm{II})$ centre. ${ }^{12}$ This solitary example markedly contrasts with the numerous studies that focus on the chemistry of phosphine-carbothioamides, $\mathrm{Ph}_{2} \mathrm{PC}(\mathrm{S}) \mathrm{NR}_{2} \cdot{ }^{13}$

In this contribution, we describe the synthesis of a phosphinoferrocene carboxamide and thioamide via lithiation and electrophilic functionalisation of 1 , and their model compounds obtained by the conventional amidation of Hdpf. The resulting hybrid ligands ${ }^{14}$ are structurally characterised through a combination of physicochemical and computational methods and further employed as donors for the soft Group 11 metal ions in order to investigate their coordination properties.

\section{Results and discussion}

\section{Preparation and characterisation of phosphino-amide donors}

Phosphinoferrocene carboxamide 2 and thioamide 3 were prepared from 1 via a one-pot, two-step procedure consisting of lithiation and subsequent quenching of the in situ generated lithio intermediate with $N, N$-dimethylcarbamoyl chloride and $N, N$-dimethylthiocarbamoyl chloride, respectively (Scheme 2). The targeted amides were purified by column chromatography and isolated in moderate to good yields (2: 46\%; 3: 81\%).

In view of the intended coordination study, the series of phosphinoamide donors was extended by the homologous secondary amide 4 (Scheme 3 ) and the known primary amide

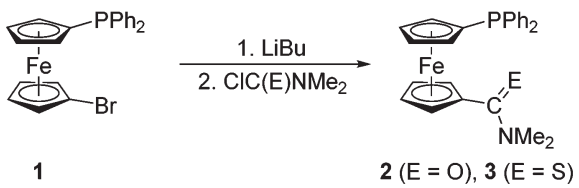

Scheme 2 Preparation of phosphinoferrocene amide 2 and thioamide 3 from 1 and the corresponding carbamoyl halides.

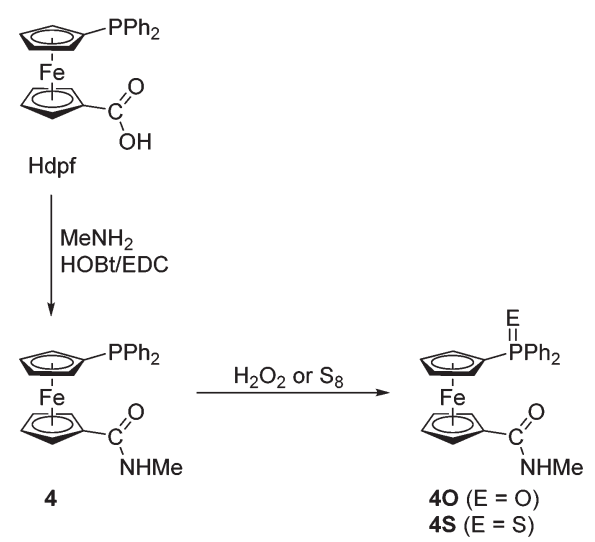

Scheme 3 Preparation of amide 4 and its corresponding P-oxide and P-sulfide. Legend: EDC = 1-ethyl-3-[3-(dimethylamino)propyl]carbodiimide, $\mathrm{HOBt}=1$-hydroxybenzotriazole.

$1^{\prime}$-(diphenylphosphino)-1-(aminocarbonyl)ferrocene $(5)^{7}$ for the purpose of comparison. The former compound was synthesised by the conventional amidation of Hdpf with methylamine in the presence of 1-ethyl-3-[3-(dimethylamino)propyl]carbodiimide (EDC) and 1-hydroxybenzotriazole (HOBt), resulting in an $87 \%$ yield after isolation by column chromatography. Amide 4 was further converted to the corresponding phosphine oxide (4O) and sulfide (4S) via standard oxidations with hydrogen peroxide and elemental sulfur, respectively.

Amides 2-4 have been characterised by multinuclear NMR and IR spectroscopy, electrospray ionisation (ESI) mass spectrometry and elemental analysis. Phosphines 2-4 display singlets in their ${ }^{31} \mathrm{P}\left\{{ }^{1} \mathrm{H}\right\}$ NMR spectra at $\delta_{\mathrm{P}} c a$. 17, close to that of Hdpf itself, ${ }^{5}$ while the signals of the P-oxidised derivatives appear shifted to lower fields ( $\delta_{\mathrm{P}}$ ca. 32 and 43 for $\mathbf{4 O}$ and $\mathbf{4 S}$, respectively). ${ }^{5,15}$ The ${ }^{1} \mathrm{H}$ and ${ }^{13} \mathrm{C}\left\{{ }^{1} \mathrm{H}\right\}$ NMR spectra reveal signals typical for the $1^{\prime}$-(diphenylphosphino)ferrocenyl moieties. The amide resonances are observed at $\delta_{\mathrm{C}} c a .170$ for the amides and at $\delta_{\mathrm{C}} 199$ for thioamide 3. As a result of the limited molecular mobility typical for conjugated amides, the signals of the methyl substituents in the spectra of the tertiary amides are observed either as a broadened singlet (2) or a pair of non-equivalent signals (3) at room temperature. On the contrary, the ${ }^{1} \mathrm{H}$ NMR signals of the methyl groups in the spectra of secondary amides 4, 40 and $\mathbf{4 S}$ are seen as NH-coupled doublets associated with quartets attributed to the $\mathrm{NH}$ proton at a lower field.

The type of amide pendant is manifested in the IR spectra, showing bands resulting from the $\mathrm{C}-\mathrm{N}$ and $\mathrm{C}=\mathrm{E}^{16}$ stretching vibrations (2: 1502 and $1650 \mathrm{~cm}^{-1}, 3: 1508 \mathrm{~cm}^{-1}$ ). The spectra 


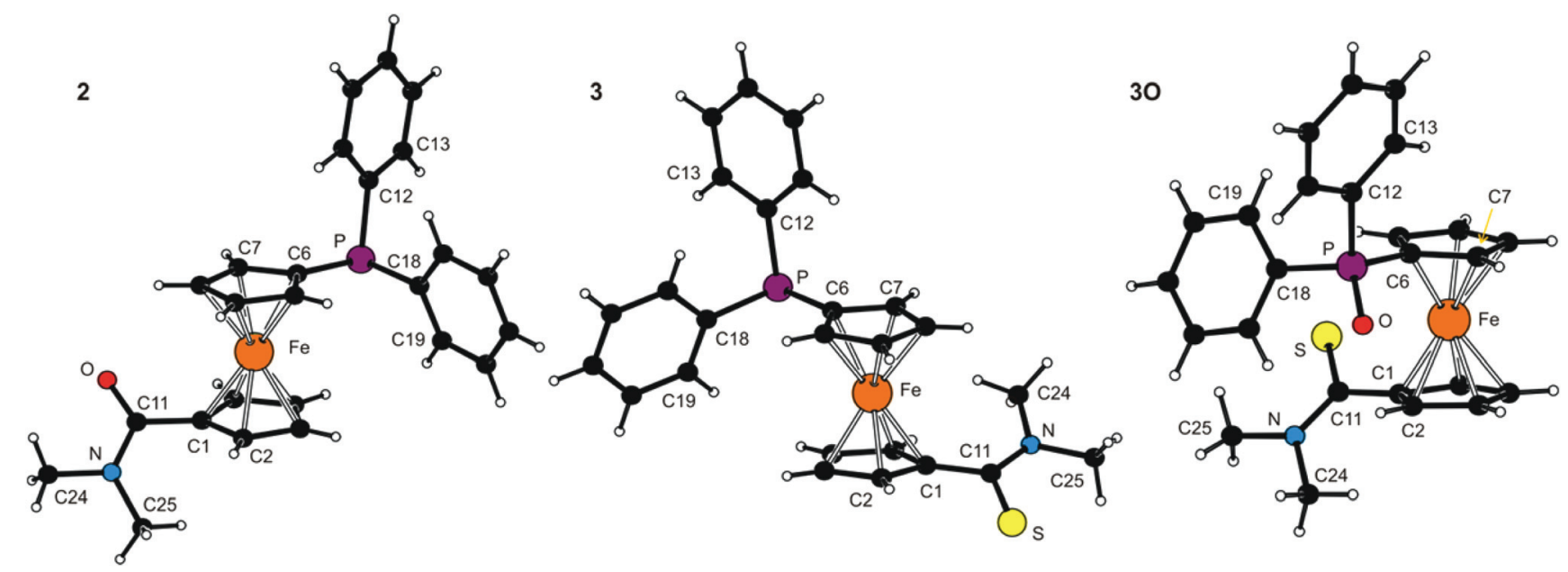

Fig. 1 PLATON plots of the molecular structures of 2, 3 and 30 (for displacement ellipsoid plots, see ESI $\dagger$ ).

of the secondary amides further display bands due to $\mathrm{NH}$ stretching modes above $3000 \mathrm{~cm}^{-1}$. Additional characterisation of 2 and 3 by DFT computations, UV-vis spectroscopy and by cyclic voltammetry are described below.

\section{Molecular structures of uncoordinated amides}

The molecular structures of all tertiary amides $(2,3$ and 30$)$ and secondary amides $\left(\mathbf{4}, \mathbf{4 0} \cdot \mathrm{CHCl}_{3}\right.$ and $\left.\mathbf{4 S}\right)$ have been determined by single-crystal X-ray diffraction analysis. The crystals of $\mathbf{3 0}$ were isolated during an attempted complexation experiment with 3, whereas those of all other compounds were grown by crystallisation of authentic samples.

The molecular structures of 2,3 and $\mathbf{3 0}$ are depicted in Fig. 1. Selected geometric parameters are summarised in Table 1. The ferrocene units in the structures of these tertiary amides exert the typical regular geometries with similar $\mathrm{Fe}-\mathrm{C}$ distances and tilt angles below $c a .6^{\circ}$ (maximum: 5.8(1) ${ }^{\circ}$ for 3 ). The ferrocene cyclopentadienyl rings in 2 and 3 assume similar anticlinal eclipsed conformations that divert the substituents into mutually distant positions. The amide plane in 2 is rotated by as much as $47.4(2)^{\circ}$ from an arrangement coplanar with its parent cyclopentadienyl ring (Cp1) with the $\mathrm{NMe}_{2}$ group pointing away from the ferrocene unit and the $\mathrm{PPh}_{2}$ substituent. The thioamide moiety in $\mathbf{3}$ is twisted considerably less $\left(26.7(2)^{\circ}\right)$ and adopts the opposite orientation with respect to the $\mathrm{PPh}_{2}$ moiety (i.e., with the $\mathrm{C}=\mathrm{S}$ bond more distant). In contrast, the ferrocene unit in $\mathbf{3 0}$ has a synclinal eclipsed conformation, which results in a rather compact structure in which both substituents are located on the same side of the ferrocene scaffold. Consequently, the rotation of the thioamide plane is increased to $41.8(2)^{\circ}$ and the orientation of the $\mathrm{C}(\mathrm{S})$ $\mathrm{NMe}_{2}$ pendant unit is changed so that the more bulky $\mathrm{NMe}_{2}$ unit is directed away from the ferrocene unit (though on the same side as the phosphine substituent). Parameters pertaining to the amide/thioamide and (diphenylphosphino)-ferrocenyl moieties appear unexceptional in view of the data reported
Table 1 Selected geometric data for tertiary amides 2, 3 and 30 (in $\AA$ and $\left.{ }^{\circ}\right)^{a}$

\begin{tabular}{llll}
\hline Parameter & $2(\mathrm{E}=\mathrm{O})$ & $3(\mathrm{E}=\mathrm{S})$ & $3 \mathrm{O}(\mathrm{E}=\mathrm{S})^{b}$ \\
\hline $\mathrm{Fe}-\mathrm{Cg} 1$ & $1.6462(8)$ & $1.6544(8)$ & $1.6413(7)$ \\
$\mathrm{Fe}-\mathrm{Cg} 2$ & $1.6464(8)$ & $1.6486(8)$ & $1.6402(7)$ \\
$\angle \mathrm{Cp} 1, \mathrm{Cp} 2$ & $2.8(1)$ & $5.8(1)$ & $4.12(9)$ \\
$\tau$ & $-151.1(1)$ & $143.5(1)$ & $71.8(1)$ \\
$\mathrm{C} 11=\mathrm{E}$ & $1.225(2)$ & $1.689(2)$ & $1.672(2)$ \\
$\mathrm{C} 11-\mathrm{N}$ & $1.356(2)$ & $1.333(2)$ & $1.337(2)$ \\
$\mathrm{E}=\mathrm{C} 11-\mathrm{N}$ & $121.7(2)$ & $121.4(1)$ & $122.3(1)$ \\
$\varphi$ & $47.4(2)$ & $26.7(2)$ & $41.8(2)$ \\
$\mathrm{N}-\mathrm{C} 24$ & $1.460(2)$ & $1.465(2)$ & $1.468(2)$ \\
$\mathrm{N}-\mathrm{C} 25$ & $1.460(2)$ & $1.464(2)$ & $1.461(2)$ \\
$\mathrm{C} 24-\mathrm{N}-\mathrm{C} 25$ & $116.3(1)$ & $113.7(2)$ & $113.0(2)$ \\
$\mathrm{P}-\mathrm{C} 6$ & $1.820(2)$ & $1.811(2)$ & $1.788(2)$ \\
$\mathrm{P}-\mathrm{C} 12$ & $1.832(2)$ & $1.835(2)$ & $1.811(2)$ \\
$\mathrm{P}-\mathrm{C} 18$ & $1.841(2)$ & $1.839(2)$ & $1.808(2)$ \\
& & &
\end{tabular}

${ }^{a}$ Definitions: $\mathrm{Cp} 1$ and $\mathrm{Cp} 2$ are the cyclopentadienyl rings $\mathrm{C}(1-5)$ and $\mathrm{C}(6-10)$, respectively. Cg1/2 denote their centroids. $\tau$ is the torsion angle $\mathrm{C} 1-\mathrm{Cg} 1-\mathrm{Cg} 2-\mathrm{C} 6$ and $\varphi$ is the dihedral angle subtended by the amide unit (C11, E, N) and the plane of its parent ring Cp1. ${ }^{b}$ Further data: $\mathrm{P}=\mathrm{O}=1.536(1) \AA$.

earlier for $\mathrm{FcCSNH}_{2},{ }^{17} \mathrm{fc}\left[\mathrm{CSNMe}_{2}\right]_{2},{ }^{9 a} \mathrm{Hdpf}$ and its P-oxide, ${ }^{5}$ $\mathrm{Ph}_{2} \mathrm{P}(\mathrm{O}) \mathrm{fcCONHCy},{ }^{7}$ and bromide $\mathbf{1}^{18}$ (Fc = ferrocenyl, fc $=$ ferrocene-1,1'-diyl).

Molecular structures of the secondary amides $\mathbf{4}, \mathbf{4 0} \cdot \mathrm{CHCl}_{3}$ and $\mathbf{4 S}$ are shown in Fig. 2. Principal geometric data are given in Table 2. The molecular parameters compare well with those reported for other structurally characterised secondary amides derived from Hdpf. $^{19}$ Similar to the tertiary amides, the ferrocene units in the structures of the secondary amides are typical with tilt angles not exceeding $c a .5^{\circ}$. A most notable difference observed across the series is again associated with the mutual orientation of the ferrocene substituents, which are near synclinal eclipsed in $\mathbf{4}$ and $\mathbf{4 0}$, staggered anticlinal in molecule 2 of $\mathbf{4 S}$, or assume an intermediate conformation between anticlinal staggered and eclipsed anticlinal eclipsed (molecule 1 of $\mathbf{4 S}$ ). 


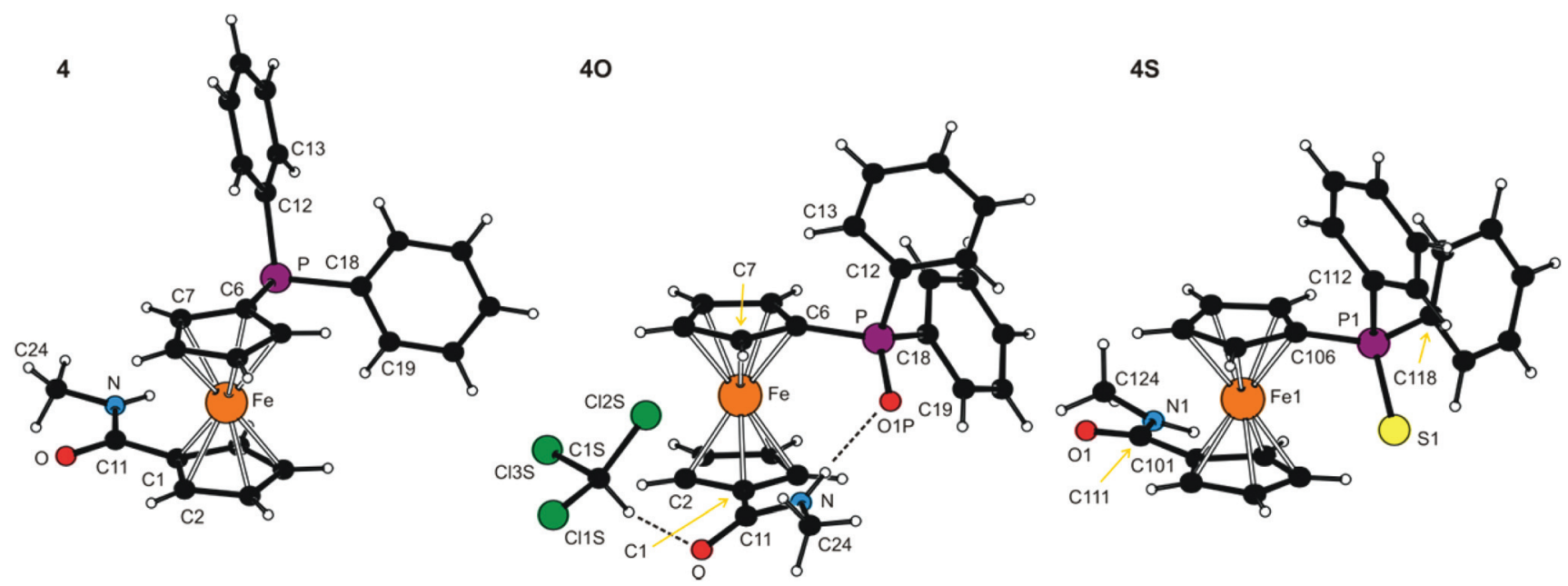

Fig. 2 PLATON plots of the molecular structures of $4,40 \cdot \mathrm{CHCl}_{3}$ and $4 \mathrm{~S}$ (molecule 1). Labelling of the second independent molecule in the structure of $4 \mathrm{~S}$ is strictly analogous. Displacement ellipsoid plots are available in the $\mathrm{ESI} \uparrow \dagger$ The $\mathrm{N}-\mathrm{H} \cdots \mathrm{O}$ and $\mathrm{C}-\mathrm{H} \cdots \mathrm{Cl}$ hydrogen bonds in the structure of $40 \cdot \mathrm{CHCl}_{3}$ are shown as dashed lines.

Table 2 Selected geometric parameters for the secondary amides 4 , 40 and 45 (in $\AA$ and $\left.{ }^{\circ}\right)^{a}$

\begin{tabular}{llll}
\hline Parameter & $\mathbf{4}(\mathrm{E}=$ void $)$ & $\mathbf{4 O}(\mathrm{E}=\mathrm{O} 1 \mathrm{P})^{b}$ & $\mathbf{4 S}(\mathrm{E}=\mathrm{S} 1 / \mathrm{S} 2)^{c}$ \\
\hline $\mathrm{Fe}-\mathrm{Cg} 1$ & $1.6462(8)$ & $1.650(1)$ & $1.640(4) / 1.662(4)$ \\
$\mathrm{Fe}-\mathrm{Cg} 2$ & $1.6420(7)$ & $1.641(1)$ & $1.643(4) / 1.639(4)$ \\
$\angle \mathrm{Cp} 1, \mathrm{Cp} 2$ & $3.2(1)$ & $1.2(1)$ & $3.2(5) / 4.7(5)$ \\
$\tau$ & $-82.6(1)$ & $71.3(2)$ & $-162.3(5) / 145.4(5)$ \\
$\mathrm{C} 11=\mathrm{O}$ & $1.242(2)$ & $1.233(3)$ & $1.222(6) / 1.233(7)$ \\
$\mathrm{C} 11-\mathrm{N}$ & $1.330(2)$ & $1.343(3)$ & $1.326(8) / 1.309(7)$ \\
$\mathrm{O}-\mathrm{C} 11-\mathrm{N}$ & $122.1(2)$ & $123.3(2)$ & $123.6(5) / 121.9(6)$ \\
$\varphi$ & $6.1(2)$ & $25.3(3)$ & $11.3(8) / 13.6(7)$ \\
$\mathrm{N}-\mathrm{C} 24$ & $1.453(2)$ & $1.456(3)$ & $1.457(9) / 1.45(1)$ \\
$\mathrm{P}=\mathrm{E}$ & $\mathrm{n} . \mathrm{a}$ & $1.495(2)$ & $1.951(3) / 1.960(3)$ \\
$\mathrm{P}-\mathrm{C} 6$ & $1.822(2)$ & $1.785(2)$ & $1.785(8) / 1.792(8)$ \\
$\mathrm{P}-\mathrm{C} 12$ & $1.835(2)$ & $1.809(2)$ & $1.826(9) / 1.813(9)$ \\
$\mathrm{P}-\mathrm{C} 18$ & $1.839(2)$ & $1.809(2)$ & $1.819(7) / 1.818(7)$
\end{tabular}

${ }^{a}$ The parameters are defined as for the tertiary amides (see Table 1). n.a. = not applicable. ${ }^{b}$ The compound crystallised in the form of stoichiometric solvate $\mathbf{4 0} \cdot \mathrm{CHCl}_{3} \cdot{ }^{c}$ Data for the two structurally independent molecules (molecule 1/molecule 2).

The rotation of the amide unit with respect to the parent cyclopentadienyl ring varies from $\mathrm{ca} .6^{\circ}$ in amide 4 to $\mathrm{ca} .25^{\circ}$ in 40. However, these structural changes seem to be (at least partly) induced by different intermolecular interactions because, unlike the tertiary amides whose solid-state structures are essentially molecular, ${ }^{20}$ the molecules of the secondary amides associate in the solid state by means of hydrogen bonds formed by the NH hydrogens. Compounds 4 and $4 \mathrm{~S}$ assemble into infinite chains consisting of molecules located around the crystallographic glide planes via $\mathrm{N}-\mathrm{H} \cdots \mathrm{O}=\mathrm{C}$ hydrogen bonds $(\mathrm{N} \cdots \mathrm{O}=2.835(2) \AA$ for 4 and $2.797(6) / 2.834(6)$ for molecules $1 / 2$ of $\mathbf{4 S}$ ). Conversely, the solvated phosphine oxide 40 forms an intramolecular hydrogen $\mathrm{N}-\mathrm{H} \cdots \mathrm{O}=\mathrm{P}$ bond towards the highly polarised ${ }^{21}$ phosphoryl oxygen $(\mathrm{N} \cdots \mathrm{O}=$ 2.838(2) $\AA$ ) rather than the amide $\mathrm{C}=\mathrm{O}$ moiety, while the $\mathrm{C}=\mathrm{O}$ group is employed in binding the solvent molecule via the soft $\mathrm{C}-\mathrm{H} \cdots \mathrm{O}$ interaction $\left(\mathrm{Cl}_{3} \mathrm{C}-\mathrm{H} \cdots \mathrm{O}=\mathrm{C}, \mathrm{C} \cdots \mathrm{O}=3.013(3) \AA\right)$.

\section{DFT and electrochemical study of amides 2 and 3}

Geometries of 2 and 3 computed by DFT methods for isolated molecules in vacuum reproduce very well those determined by X-ray crystallography in the solid state (for an overlap of the computed and experimentally determined molecular structures, see $\mathrm{ESI}^{\dagger}$ ). Whereas the calculated interatomic distances differ from the experimental ones by less than $c a$. $0.04 \AA$ (the mean difference being only $0.01 \AA$ ), the interatomic angles show more pronounced variation (maximum $14^{\circ}$, average difference: $1-3^{\circ}$ ) due to changes in conformation. ${ }^{22}$ The dihedral angle of the cyclopentadienyl planes and $\tau$ parameter calculated for amide 2 are $2^{\circ}$ and $-174^{\circ}$, respectively. The amide moiety in the DFT optimised structure has similar orientation to the solid state structure with twist angle $\varphi$ of $39^{\circ}$. In the case of thioamide 3 , the $\tau$ and $\varphi$ angles of $149^{\circ}$ and $26^{\circ}$, respectively, correspond also well with the crystal structure data ( $c f$. data in Table 1).

The LUMO, HOMO and two next molecular orbitals below HOMO are depicted in Fig. 3. In the case of 2, the HOMO and HOMO-1 show dominant contributions from d orbitals on Fe, while for 3, the HOMO consists mainly of non-bonding orbital located on sulfur (lone pair). The next two lower molecular orbitals of 3 are of similar nature as HOMO and HOMO-1 of 2 (similar to diagonal relationship), but with certain contribution from atomic orbitals located on the sulfur atom and with somewhat lower energies. This corresponds well with the lower ionisation potential and higher softness of sulfur with respect to oxygen. This principal difference in the structure of the highest occupied molecular orbitals is most likely responsible for the different electrochemical behaviour of 2 and 3 (vide infra). 

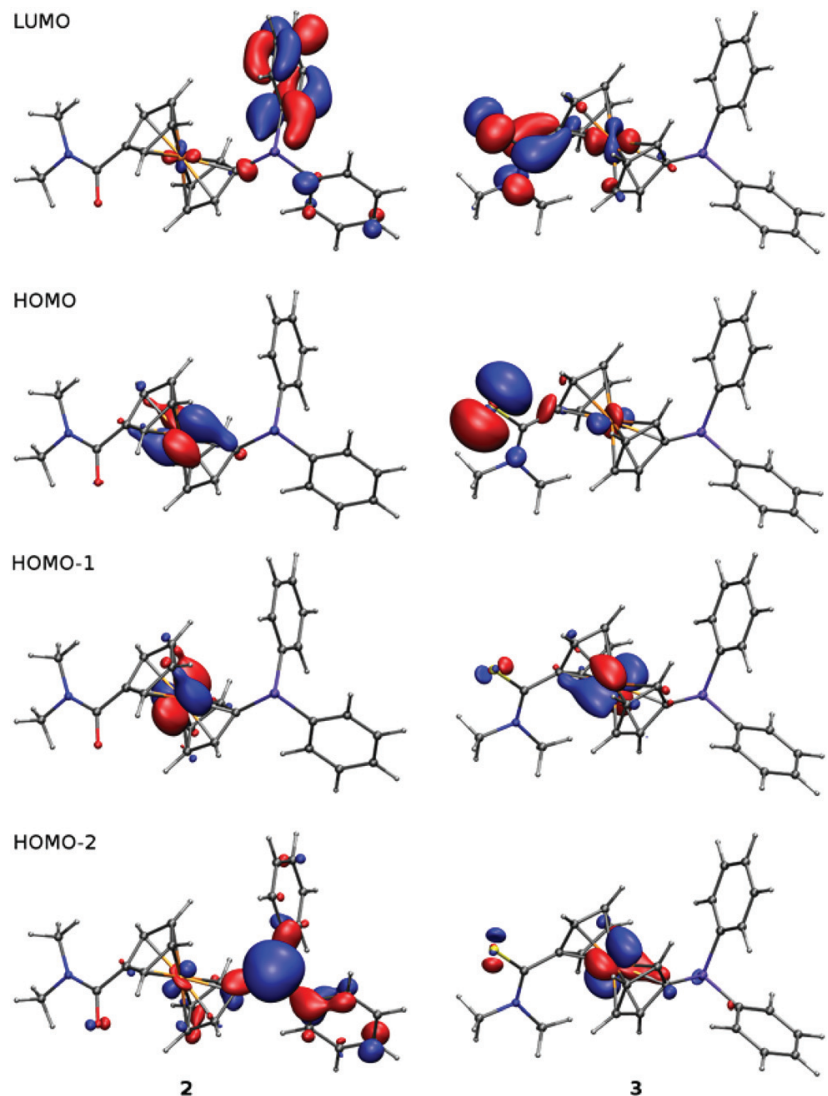

Fig. 3 Plots of LUMO, HOMO and two lower molecular orbitals of 2 and 3 showing contours at the \pm 0.05 a.u. level.

Changes in electronic structure associated with the (formal) replacement of the amide oxygen with sulfur prompted us to investigate the representative amides 2 and 3 by UV-vis spectroscopy and by electrochemical methods. The UV-vis spectra (Fig. 4) comprise single bands (with a shoulder at lower energies) located at the foot of a more intense bands extending from the UV region. This band in the spectrum of 2

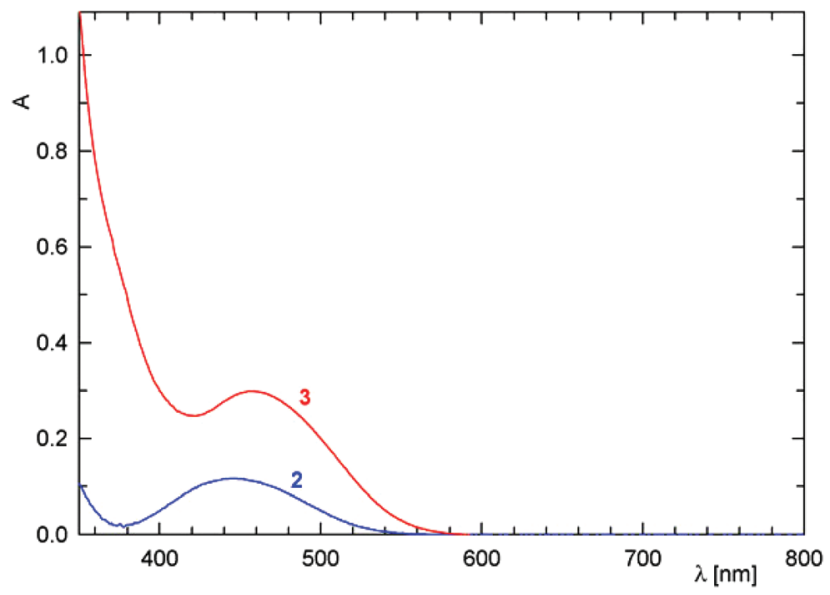

Fig. 4 UV-vis spectra of 2 (blue line) and 3 (red line) recorded in 1,2dichloroethane solutions ( $c=5 \times 10^{-4} \mathrm{M}$, optical path $10 \mathrm{~mm}$ ).

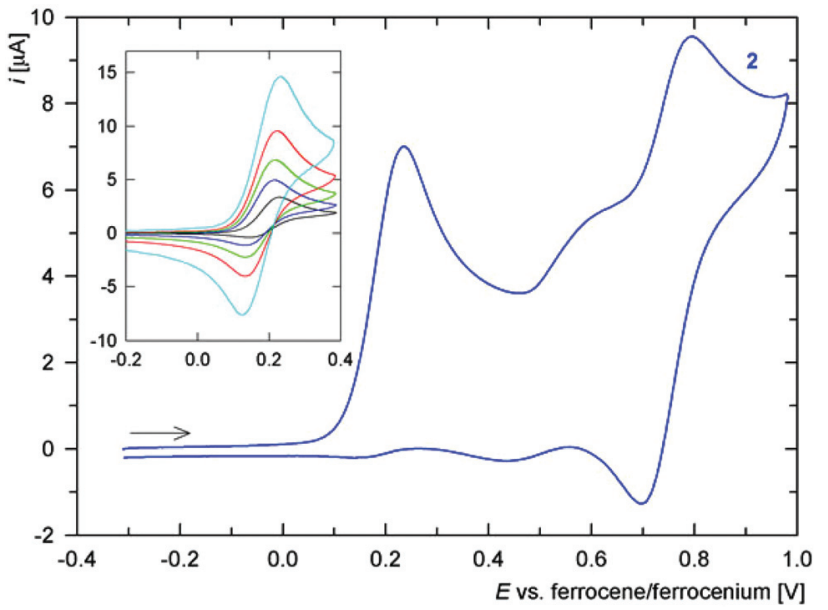

Fig. 5 Cyclic voltammogram of amide 2 as recorded at Pt disc electrode in 1,2-dichloroethane at $0.1 \mathrm{~V} \mathrm{~s}^{-1}$ scan rate (the arrow indicates the scan direction). The inset shows partial cyclic voltammograms recorded at different scan rates (black: $20 \mathrm{mV} \mathrm{s}^{-1}$, blue: $50 \mathrm{mV} \mathrm{s}^{-1}$, green: $0.1 \mathrm{mV} \mathrm{s}^{-1}$, red: $0.2 \mathrm{~V} \mathrm{~s}^{-1}$, and cyan: $0.5 \mathrm{~V} \mathrm{~s}^{-1}$ ).

is observed at $445 \mathrm{~nm}$, shifted slightly to lower energies as compared with ferrocene itself $(440 \mathrm{~nm}$; forbidden $\mathrm{d}-\mathrm{d}$ transition). ${ }^{23}$ In the spectrum of 3 , the absorption band is significantly red-shifted (458 $\mathrm{nm}$ ) and also more intense, presumably owing to a more extensive conjugation. ${ }^{24}$

Cyclic voltammogram of amide 2 (Fig. 5) displays a oneelectron oxidation at $E^{\circ \prime} c a .0 .17 \mathrm{~V} v s$. ferrocene/ferrocenium. The oxidation, which can be attributed to the $\mathrm{Fe}^{\mathrm{II}} / \mathrm{Fe}^{\mathrm{III}}$ couple (electron removal from HOMO located predominantly at the ferrocene unit, see above), is associated with some follow-up processes that render it quasi-reversible and also give to rise to additional redox waves at higher potentials. Nonetheless, chemical reactions of the electrochemically generated species are relatively slow because the ratio of the cathodic and anodic peak currents $\left(i_{\mathrm{pc}} / i_{\mathrm{pa}}\right)$ significantly increases with increasing scan rate (see inset in Fig. 5), limiting to unity. Such behaviour resembles that of the parent acid Hdpf. ${ }^{5}$ The fact that the oxidation of the ferrocene unit is shifted to less positive potential than that of $\operatorname{Hdpf}\left(E^{\circ} c a .0 .31 \mathrm{~V}\right.$ in $\left.\mathrm{MeCN}\right)$ is in accordance with the lower electron-withdrawing ability of the amide moiety as compared with the carboxyl group ( $c f$. the Hammett $\sigma_{\mathrm{p}}$ constants: 0.36 for $\mathrm{CONH}_{2}$, and 0.45 for $\left.\mathrm{CO}_{2} \mathrm{H}\right){ }^{25}$

The redox behaviour of thioamide 3 is much less clear-cut (Fig. 6). The compound undergoes an irreversible oxidation at $c a$. $0.02 \mathrm{~V}$ (anodic peak potential, $E_{\mathrm{pa}}$, is given), which is followed by several ill-defined irreversible oxidations that replace the original composite oxidative wave during the second and following scans (even at $1 \mathrm{~V} \mathrm{~s}^{-1}$ ). Such a response may well correspond with the properties of the HOMO orbital, which encompasses both ferrocene unit and the thioamide moiety.

\section{DFT study of amide group conformation}

The relatively high and varying twisting of the amide pendant observed in the solid-state structures of free phosphinoamides 


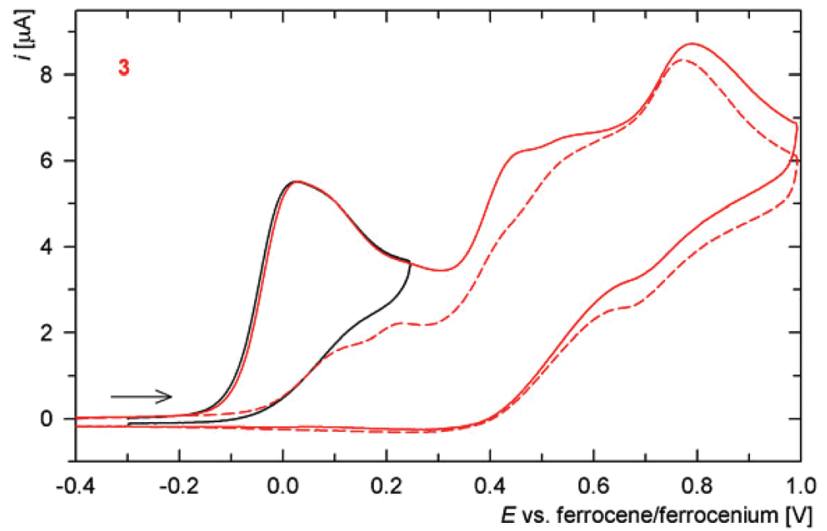

Fig. 6 Full (red line) and partial (black line) cyclic voltammograms of 3 as recorded at $\mathrm{Pt}$ disc electrode in 1,2-dichloroethane at $0.1 \mathrm{~V} \mathrm{~s}^{-1}$ scan rate. The arrow indicates the scan direction and the second scan is distinguished by a dashed line.

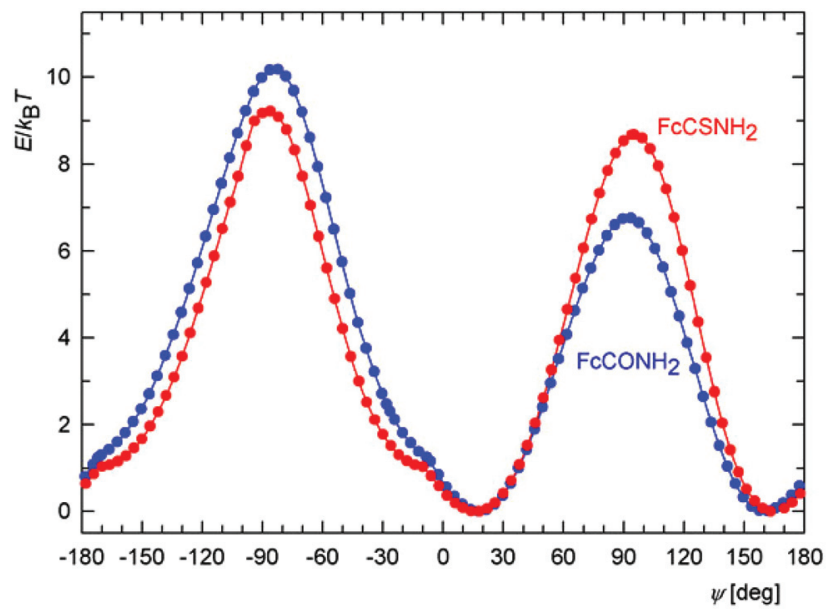

Fig. 7 Calculated energy dependence on the torsion angle $\psi$ for $\mathrm{FcCONH}_{2}$ (blue) and $\mathrm{FcCSNH}_{2}$ (red) at $T=300 \mathrm{~K}$.

led us further to investigate the influence of the dihedral angle subtended by the amide plane $\{\mathrm{C}, \mathrm{N}, \mathrm{E}\}$ and its parent cyclopentadienyl ring on the overall energy of the isolated model molecules of $\mathrm{FcCONR}_{2}$ and $\mathrm{FcCSNR}_{2}(\mathrm{R}=\mathrm{H}$ and Me) by DFT calculations. Attention was paid to this parameter mainly because it could significantly affect the coordination properties of the phosphinoamides, being responsible for an efficient approach of the amide moieties to a metal centre.

For the sake of a simpler definition, the dihedral angle $\varphi$ was replaced with the torsion angle $\mathrm{C} 2-\mathrm{C} 1-\mathrm{C} 11-\mathrm{E}(\psi)$. The energy profiles calculated as a function of this angle for FcCONH ${ }_{2}$ and $\mathrm{FcCSNH}_{2}$ (Fig. 7) show two equivalent minima corresponding to enantiomers. The maxima belong to conformations with amide groups perpendicular to the parent cyclopentadienyl rings, with the higher in energy corresponding to the conformation in which the $\mathrm{NH}_{2}$ unit is directed closer to the $\mathrm{Fe}$ atom. The practically coincident minima for both amides exhibit twists of the amide group of $18^{\circ}$. In the case of the more bulky $N, N$-dimethyl derivatives, $\mathrm{FcC}(\mathrm{E}) \mathrm{NMe}_{2}$, the twisting increases to $35^{\circ}$ and $37^{\circ}$ for $\mathrm{E}=\mathrm{O}$ and $\mathrm{S}$, respectively, presumably for steric reasons. The former value corresponds with that determined in the solid state $\left(\mathrm{FcCONMe}_{2}: 36 / 37^{\circ}\right.$ for two independent molecules). ${ }^{26,27}$

Importantly, the curvature of the energy landscape near the minima for both $\mathrm{FcCONH}_{2}$ and $\mathrm{FcCSNH}_{2}$ allows for an essentially free change of $\psi$ by approximately $20^{\circ}$ in both directions at room temperature, i.e., within the energy change of $1 k_{\mathrm{B}} \mathrm{T}$ (where $k_{\mathrm{B}}$ is the Boltzmann constant). In this interval, the twist angle can thus be controlled via an interplay between energy changes reflecting the extent of conjugation, steric effects, coordination and intermolecular interactions (the latter in the solid state).

Another notable feature in the energy profiles concerns small changes in the slope for conformers whose amide groups are nearly coplanar with their bonding cyclopentadienyl rings $\left(\psi \approx 10^{\circ}\right)$. These changes result from the potential energy surface (PES) crossing other surface corresponding to an inversion of the pyramidal $\mathrm{NH}_{2}$ moiety because the two surfaces coincide for the planar arrangement of the $\mathrm{NH}_{2}$ groups (for clarity, only the PES with the lower energy is shown in Fig. 7).

\section{Synthesis of copper(I) and silver(I) complexes}

In order to fully exploit the donor moieties available in $\mathbf{2 - 5}$, coordination study with the soft $\mathrm{Cu}(\mathrm{I})$ and $\mathrm{Ag}(\mathrm{I})$ ions was undertaken using metal precursors devoid of any firmly bound ligands (e.g., halides) and coordinating anions that could possibly compete with the donor groups offered by the amidophosphine ligands. Hence, the complexation reactions were performed at the ligand-to-metal ratio of $2: 1$ using [Cu$\left.(\mathrm{MeCN})_{4}\right]\left[\mathrm{BF}_{4}\right]$ and $\mathrm{AgClO}_{4}$ as the metal sources (Scheme 4).

These precursors reacted identically with all of the amides to afford bis-chelate complexes of the type $\left[\mathrm{M}\left(\mathrm{L}-\kappa^{2} O, P\right)_{2}\right] \mathrm{X}$. The reaction of thioamide 3 with $\left[\mathrm{Cu}(\mathrm{MeCN})_{4}\right]\left[\mathrm{BF}_{4}\right]$ afforded an analogous compound $\mathbf{6 d}$, the structure of which, together with other representatives $(\mathbf{6} \mathbf{b}, \mathbf{7 b}$ and $\mathbf{6 d}$; vide infra), was unambiguously confirmed by single-crystal X-ray diffraction analysis. In contrast, the reaction of 3 with silver(I) perchlorate produced an evidently different product (7d) exhibiting properties very different from those of the rest of the series: the compound readily precipitated from the reaction mixture and was practically insoluble in common organic solvents (including DMSO- $\mathrm{d}_{6}$ ), which in turn precluded its detailed characterisation by solution techniques (e.g., NMR spectroscopy). This finding alerted us to investigate this material in more detail. Fortunately, X-ray quality crystals were obtained when the educts were allowed to mix slowly by liquid-phase diffusion. The isolated crystals proved to be identical with $\mathbf{7 d}$ obtained by direct mixing of the starting materials, as evidenced by the IR spectra.

The structure determination revealed $\mathbf{7 d}$ to be a "dimer", wherein the thioamide coordinates in a P,S-bidentate fashion to one silver(I) centre and simultaneously acts as a bridge towards the other $\mathrm{Ag}(\mathrm{I})$ ion through its sulfur atom. The coordi- 


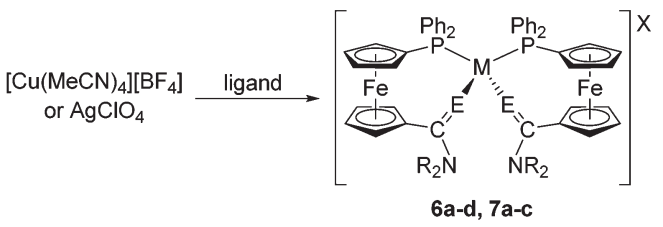

\begin{tabular}{cllll}
\hline complex & $\mathrm{M}$ & $\mathrm{E}$ & $\mathrm{NR}_{2}$ & $\mathrm{X}$ \\
\hline $6 \mathbf{6}$ & $\mathrm{Cu}$ & $\mathrm{O}$ & $\mathrm{NH}_{2}$ & $\mathrm{BF}_{4}$ \\
$6 \mathbf{6}$ & $\mathrm{Cu}$ & $\mathrm{O}$ & $\mathrm{NHMe}$ & $\mathrm{BF}_{4}$ \\
$6 \mathbf{c}$ & $\mathrm{Cu}$ & $\mathrm{O}$ & $\mathrm{NMe}_{2}$ & $\mathrm{BF}_{4}$ \\
$6 \mathbf{d}$ & $\mathrm{Cu}$ & $\mathrm{S}$ & $\mathrm{NMe}_{2}$ & $\mathrm{BF}_{4}$ \\
$7 \mathbf{a}$ & $\mathrm{Ag}$ & $\mathrm{O}$ & $\mathrm{NH}_{2}$ & $\mathrm{ClO}_{4}$ \\
$7 \mathbf{7 b}$ & $\mathrm{Ag}$ & $\mathrm{O}$ & $\mathrm{NHMe}$ & $\mathrm{ClO}_{4}$ \\
$7 \mathbf{c}$ & $\mathrm{Ag}$ & $\mathrm{O}$ & $\mathrm{NMe}_{2}$ & $\mathrm{ClO}_{4}$
\end{tabular}

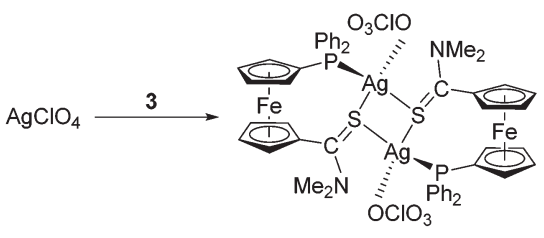

$7 d$

Scheme 4 Synthesis of $\mathrm{Cu}(1)$ and $\mathrm{Ag}\left({ }_{1}\right)$ complexes.

nation sphere is completed by O-bonded perchlorate, resulting in tetrahedral coordination around the chemically equivalent metal centres. As the consequence, the complex has an overall $1: 1$ ligand-to-metal stoichiometry, which clearly differentiates $7 \mathbf{d}$ from the rest of the $\mathrm{Cu}(\mathrm{I})$ and $\mathrm{Ag}(\mathrm{I})$ complexes.

Complexes 6 and 7 were characterised by elemental analysis, IR and NMR spectroscopy, and ESI MS spectrometry. The coordination of the amidophosphine ligands in these compounds is clearly manifested in the ${ }^{31} \mathrm{P}$ NMR spectra via a shift of the ${ }^{31} \mathrm{P}$ NMR signal to lower fields. The ${ }^{31} \mathrm{P}$ NMR signals are observed as singlets at approximately $-11 \mathrm{ppm}$ for the $\mathrm{Cu}(\mathrm{I})$ complexes 6a-d, and as ${ }^{107 / 109} \mathrm{Ag}$-coupled doublets at ca. 3-4 ppm for 7a-c. Compound 7d gives rise to a broad doublet at $\delta_{\mathrm{P}}-0.3$ with ${ }^{1} J(\mathrm{Ag}, \mathrm{P}) \approx 510 \mathrm{~Hz}$. It is also noteworthy that the ${ }^{31} \mathrm{P}$ and ${ }^{1} \mathrm{H}$ NMR signals are typically broadened, indicating that some dynamic processes are taking place in the solution. In their ESI mass spectra, the "mononuclear" complexes 6a-d and $7 \mathbf{a}-\mathbf{c}$ exhibit signals of the cations $\left[\mathrm{ML}_{2}\right]^{+}$and their fragments $[\mathrm{ML}]^{+}$. The spectrum of the disilver(I) species $\mathbf{7 d}$ is dominated by the ions due to $[\operatorname{Ag}(3)]^{+}$at $\mathrm{m} / \mathrm{z} \quad 563 / 566$ and further shows additional signals attributable to $[\mathrm{Ag}(3)$ $\left.\left(\mathrm{CH}_{3} \mathrm{OH}\right)\right]^{+}(\mathrm{m} / \mathrm{z} 596 / 599)$. All these results (shifts of the ${ }^{1} \mathrm{H}$ and ${ }^{31} \mathrm{P}$ NMR signals and species observed in the ESI MS spectra) suggest the solid state structures to be retained even in solution, though perhaps with some structural dynamics.

Finally, the presence of the counter anions is reflected in the IR spectra, showing composite intense bands resulting from the $\nu_{3}$ vibrations ${ }^{28}$ of the tetrahedral ions $\mathrm{BF}_{4}{ }^{-}$and $\mathrm{ClO}_{4}{ }^{-}$ at $c a .1030-1095 \mathrm{~cm}^{-1}$ and $1050-1130 \mathrm{~cm}^{-1}$, respectively.

The anticipated dynamic and possibly hemilabile coordination ${ }^{29}$ of the phosphinoamide donors was proven by a seren- dipitous isolation of several crystals of a solvento complex, $\left[\mathrm{Cu}\left(5-\mathrm{\kappa}^{2} O, P\right)(5-\mathrm{k} P)\left(\mathrm{CHCl}_{3}-\mathrm{KCl}\right)\right]\left[\mathrm{BF}_{4}\right]\left(6 \mathbf{a}^{\prime}\right)$, which was isolated during an attempted crystallisation of $\mathbf{6 a}$ and structurally characterised. It is noteworthy that this solvento complex ensued from a copper(I) complex whose amide substituents $\left(\mathrm{NH}_{2}\right)$ provide the lowest steric protection and donating ability among the amides studied and comprise oxygen as a hard donor atom (N.B. $\mathrm{Cu}(\mathrm{I})$ is softer than $\mathrm{Ag}(\mathrm{I})$ according to the absolute hardness scale ${ }^{30}$ ).

\section{Molecular structures of the $\mathrm{Cu}(\mathrm{I})$ and $\mathrm{Ag}(\mathrm{I})$ complexes}

Crystallisation of the "bulk" samples provided single crystals of $\mathbf{6} \mathbf{b} \cdot 1 / 4 \mathrm{CHCl}_{3}, \mathbf{6 d} \cdot 2 \mathrm{CHCl}_{3}$, and $7 \mathbf{b} \cdot \mathrm{CHCl}_{3}$, which were used for structure determination. The crystals of $\mathbf{7 d}$ had to be grown by reactive diffusion because of poor solubility, making any recrystallisation impossible (see Experimental), whereas those of $6 \mathbf{a}^{\prime} \cdot \mathrm{CHCl}_{3}$ were obtained unintentionally upon attempted crystallisation of $\mathbf{6 a}$.

As indicated by the formulae given above, the compounds tend to retain crystallisation solvents in their structure, which often become disordered in structural voids defined by the bulky complex molecules. A similar effect affects the counter anions, which are considerably smaller than the cations they are associated with, and even some peripheral molecular parts (e.g., phenyl rings).

The crystal structure of $\mathbf{6 d} \cdot 2 \mathrm{CHCl}_{3}$ is shown in Fig. 8 (structural drawings of the analogous complexes $6 \mathbf{b} \cdot 1 / 4 \mathrm{CHCl}_{3}$ and $7 \mathbf{b} \cdot \mathrm{CHCl}_{3}$ are presented in the ESI $\dagger$ ). Relevant geometric parameters for all three complexes are provided in Table 3. The structures support the formulation, revealing tetrahedral coordination environments around the metal centres constituted by two P,E-chelating ( $\mathrm{E}=\mathrm{O}$ or $\mathrm{S}$ ) amidophosphine ligands. An inspection of the interligand angles reveals pronounced angular distortion of the coordination sphere resulting from the different steric demands of the donor moieties. In the pair of complexes derived from ligand 4 (i.e., $\mathbf{6 b}$. $1 / 4 \mathrm{CHCl}_{3}$ and $7 \mathbf{b} \cdot \mathrm{CHCl}_{3}$ ), the interligand angles increase from $\mathrm{O}-\mathrm{M}-\mathrm{O}$ via $\mathrm{O}-\mathrm{M}-\mathrm{P}$ to $\mathrm{P}-\mathrm{M}-\mathrm{P}$. Such a feature, as well as the

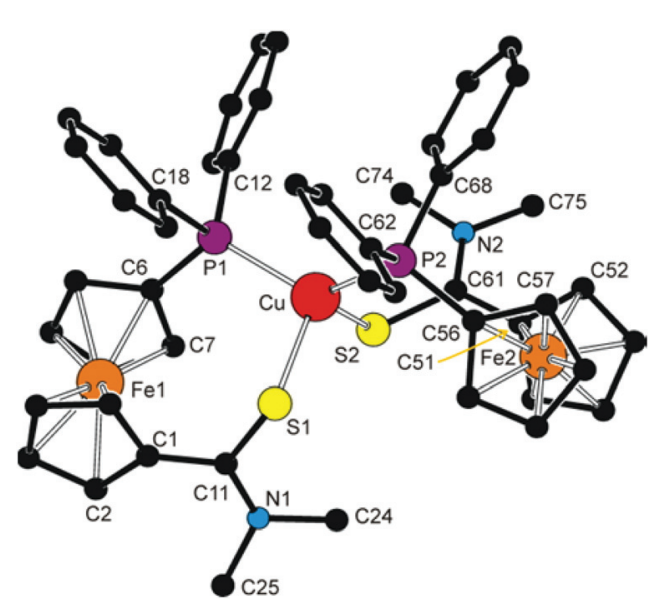

Fig. 8 View of the cation in the structure of $6 \mathrm{~d} \cdot 2 \mathrm{CHCl}_{3}$. The hydrogen atoms are omitted for clarity. 
Table 3 Selected geometric data for the bis-chelates $6 \mathrm{~b} \cdot 1 / 4 \mathrm{CHCl}_{3}, 6 \mathrm{~d} \cdot 2 \mathrm{CHCl}_{3}$ and $7 \mathrm{~b} \cdot \mathrm{CHCl}_{3}$ and for the related solvento complex $6 \mathrm{a}^{\prime} \cdot \mathrm{CHCl}_{3}$ (in $\AA$ and $\left.{ }^{\circ}\right)^{a}$

\begin{tabular}{|c|c|c|c|c|c|c|c|}
\hline \multirow{2}{*}{$\begin{array}{l}\text { Compound } \\
\text { Parameter }\end{array}$} & \multicolumn{2}{|c|}{$\begin{array}{l}\mathbf{6 b} \cdot 1 / 4 \mathrm{CHCl}_{3} \\
(\mathrm{M} / \mathrm{E}=\mathrm{Cu} / \mathrm{O} 1, \mathrm{O} 2)\end{array}$} & \multicolumn{2}{|c|}{$\begin{array}{l}\mathbf{6 d} \cdot 2 \mathrm{CHCl}_{3} \\
(\mathrm{M} / \mathrm{E}=\mathrm{Cu} / \mathrm{S} 1, \mathrm{~S} 2)\end{array}$} & \multirow{2}{*}{ 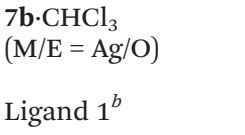 } & \multicolumn{2}{|c|}{$\begin{array}{l}\mathbf{6 a}^{\prime} \cdot \mathrm{CHCl}_{3} \\
(\mathrm{M} / \mathrm{E}=\mathrm{Cu} / \mathrm{O} 1, \mathrm{O} 2)^{c}\end{array}$} \\
\hline & Ligand 1 & Ligand 2 & Ligand 1 & Ligand 2 & & Ligand $1^{d}$ & Ligand $2^{d}$ \\
\hline $\mathrm{M}-\mathrm{P}$ & $2.2469(7)$ & $2.2256(8)$ & $2.2842(5)$ & $2.2636(5)$ & $2.4256(6)$ & $2.251(1)$ & $2.233(1)$ \\
\hline M-E & $2.174(2)$ & $2.102(2)$ & $2.3866(6)$ & $2.3951(7)$ & $2.468(2)$ & n.a. & $2.006(3)$ \\
\hline P-M-P [E-M-E] & $125.79(3)$ & {$[93.06(9)]$} & $127.32(2)$ & {$[108.24(2)]$} & $142.99(3)[80.20(6)]$ & $128.17(4)$ & n.a. \\
\hline $\mathrm{P}-\mathrm{M}-\mathrm{E} 1$ & $104.09(6)$ & $109.40(6)$ & $105.59(2)$ & $100.17(2)$ & $115.50(5)$ & n.a. & n.a. \\
\hline $\mathrm{Fe}-\mathrm{Cg} 2$ & 1.639(1) & $1.646(1)$ & $1.644(1)$ & $1.647(1)$ & $1.640(1)$ & $1.649(2)$ & $1.646(2)$ \\
\hline$\angle \mathrm{Cp} 1, \mathrm{Cp} 2$ & $1.0(2)$ & $4.0(2)$ & $3.5(2)$ & $7.5(2)$ & $1.0(2)$ & $2.7(2)$ & $2.2(2)$ \\
\hline$\tau$ & $-49.4(2)$ & $-68.2(2)$ & $-59.5(2)$ & $-15.2(2)$ & $-69.5(2)$ & $101.0(3)$ & $-59.4(3)$ \\
\hline $\mathrm{C}=\mathrm{E}$ (amide) & $1.240(4)$ & $1.228(3)$ & $1.711(2)$ & $1.714(2)$ & $1.231(3)$ & $1.250(4)$ & $1.271(3)$ \\
\hline $\mathrm{C}-\mathrm{N}$ (amide) & $1.324(4)$ & $1.331(3)$ & $1.325(3)$ & $1.323(3)$ & $1.337(4)$ & $1.320(5)$ & $1.312(4)$ \\
\hline $\mathrm{E}=\mathrm{C}-\mathrm{N}$ (amide) & 121.1(3) & $121.4(2)$ & $120.0(2)$ & $121.1(2)$ & $122.0(2)$ & $121.9(3)$ & $118.6(3)$ \\
\hline$\varphi$ & $19.3(4)$ & $27.9(3)$ & $11.1(2)$ & $39.1(2)$ & $15.5(3)$ & $9.0(4)$ & $19.8(3)$ \\
\hline
\end{tabular}

${ }^{a}$ Definitions: $\mathrm{Cp} 1$ and $\mathrm{Cp} 2$ are the amide- and phosphine-substituted cyclopentadienyl rings, respectively. Cg1/2 are their centroids. $\tau$ is the torsion angle $\mathrm{C} 1-\mathrm{Cg} 1-\mathrm{Cg} 2-\mathrm{C} 6$ and $\varphi$ is the dihedral angle subtended by the amide unit $(\mathrm{E}=\mathrm{C} 1-\mathrm{N})$ and the plane of its parent ring $\mathrm{Cp} 1$. n.a. $=$ not applicable. ${ }^{b}$ Only one set of distances and angles available because of the imposed symmetry. ${ }^{c}$ Further data: $\mathrm{Cu}-\mathrm{Cl} 1=3.138(2) ; \mathrm{Cl} 1-\mathrm{Cu}-\mathrm{P} 1=$ 107.90(4), $\mathrm{Cl} 1-\mathrm{Cu}-\mathrm{P} 2=86.96(4), \mathrm{Cl} 1-\mathrm{Cu}-\mathrm{O} 2=91.8(1) .{ }^{d}$ Ligand $1=\mathrm{P}$-monodentate 5, ligand $2=\mathrm{O}$,P-chelating 5.

individual ligand-donor bond lengths, correspond with those reported for $\left[\mathrm{Cu}\left(\mathrm{Ph}_{2} \mathrm{PfcCONHCH} \mathrm{CO}_{2} \mathrm{Me}-\mathrm{K}^{2} \mathrm{O}, \mathrm{P}\right)_{2}\right]\left(\mathrm{CF}_{3} \mathrm{SO}_{3}\right){ }^{31}$

Upon going from $\mathbf{6 b} \cdot 1 / 4 \mathrm{CHCl}_{3}$ to $7 \mathbf{b} \cdot \mathrm{CHCl}_{3}$, a lengthening of the M-P (by $c a .0 .2 \AA$ ) and, particularly, the $\mathrm{M}-\mathrm{O}$ bonds (from $c a .2 .10 / 2.17 \AA$ for $\mathrm{Cu}(\mathrm{I})$ to $2.47 \AA$ for $\mathrm{Ag}(\mathrm{I})$ ) is observed owing to the presence of a larger central atom in the $\operatorname{Ag}(\mathrm{I})$ complex. The fact that the $\mathrm{Cu}-\mathrm{O}$ distances in the structure of the former compound differ significantly $(0.07 \AA)$ can be associated with a relatively weaker coordination of the hard donor group, which may in turn allow for structural distortions without any dramatic destabilisation (increase in the overall energy; $c f$. the DFT calculations above). On the other hand, the bond lengths within the amide pendant change only marginally upon coordination (see the data for $\mathbf{4}$ above) but the ligand undergoes conformational reorganisation. The ferrocene-bound donor moieties are rotated closer to each other and the amide planes are twisted so as their oxygen atoms can reach the metal centre.

The $\mathrm{Cu}(\mathrm{I})$ complex bearing the thioamide ligands, 6d $\cdot 2 \mathrm{CHCl}_{3}$, also possesses a tetrahedral structure, but because of longer $\mathrm{Cu}-\mathrm{S}$ bonds, it appears to be more sterically relaxed. This is manifested in the interligand angles among which the $\mathrm{S}-\mathrm{Cu}-\mathrm{S}$ is no longer the most acute. Notably, the two structurally independent P,S-chelating ligands in the structure of $\mathbf{6 d}$ differ by conformation as evidenced by the $\tau$ and $\varphi$ angles (Table 3; N.B. similar though less pronounced differences can be observed in the structure of $\mathbf{6 b}$ ).

Opening of one of the chelate rings, such in the structure of $\mathbf{6 a}^{\prime} \cdot \mathrm{CHCl}_{3}$ (Fig. 9 and Table 3), does not result in an equalisation of the interligand angles $\left(c a .87-128^{\circ}\right)$, presumably because the amide oxygen is replaced with a relatively bulky chloroform molecule. The $\mathrm{Cu}-\mathrm{Cl} 1$ distance of 3.138(2) $\AA$ approaches the threshold of the van der Waals contacts $\left(3.15 \AA^{32}\right)$. According to a search in the Cambridge Structural Database (CSD) ${ }^{33}$ analogous $\mathrm{Cu} \cdots \mathrm{Cl}-\mathrm{CHCl}_{2}$ interactions are rare and can be detected in the crystal structures of chloroform solvates of molecular triangles $\left(\mathrm{Cu}_{3}\right)^{34}$ and squares $\left(\mathrm{Cu}_{4}\right)^{35}$ built up from bis(acetylacetonate) ligands and $\mathrm{Cu}(\mathrm{II})$ ions, in which the chloroform occupies an apical position in a square pyramid around the $\mathrm{Cu}(\mathrm{II})$ ions $(\mathrm{Cu} \cdots \mathrm{Cl} \approx 3.11-3.25 \AA)$.

The different roles that the two amidophosphine ligands play in the complex cation of $\mathbf{6 a}^{\prime}$ are reflected in their conformations. Thus, the donor substituents in the chelating ligand adopt a conformation between synclinal staggered and synclinal eclipsed $\left(\tau \approx-59^{\circ}\right)$, and the amide planes are rotated by ca. $20^{\circ}$ with respect to the parent cyclopentadienyl ring. On the other hand, the P-bound ligand assumes a more opened anticlinal conformation $\left(\tau \approx 101^{\circ}\right)$ and the amide plane is twisted by only $c a$. $9^{\circ}$. The $\mathrm{C}=\mathrm{O}$ distances are affected only marginally but in the expected manner as the coordinated $\mathrm{C}=\mathrm{O}$ bond is $c a .0 .02 \AA$ longer than the uncoordinated one.

$\mathrm{NH}$ protons in the structures of complexes with coordinated 4 (i.e., $\mathbf{6 b}$ and $\mathbf{7 b}$ ) are involved in hydrogen bonding to the respective counter anion in the crystal state. Those in molecules of $\mathbf{6} \mathbf{a}^{\prime}$ interconnect the complex units into dimers positioned around the inversion centres (Fig. 9). In the latter case, each P-bound ligand is linked to its inversion-related counterpart via a pair of $\mathrm{N}-\mathrm{H} \cdots \mathrm{O}=\mathrm{C}$ hydrogen bonds from the $\mathrm{NH}$ hydrogen closer to the amide oxygen, whereas the other hydrogen forms an $\mathrm{N}-\mathrm{H} \cdots \mathrm{F}$ hydrogen bridge to one of the $\mathrm{BF}_{4}{ }^{-}$ anions. Amide hydrogens in the $\mathrm{P}, \mathrm{O}-\mathrm{ch}$ elating ligand participate in similar interactions towards the oxygen in the P-monodentate ligand (O1) bonded to the same metal centre and towards another $\mathrm{BF}_{4}$ fluorine, respectively.

As it was stated above, complex 7d (Fig. 10 and Table 4) is a dimer, in which the phosphinoamide ligands coordinate in a 

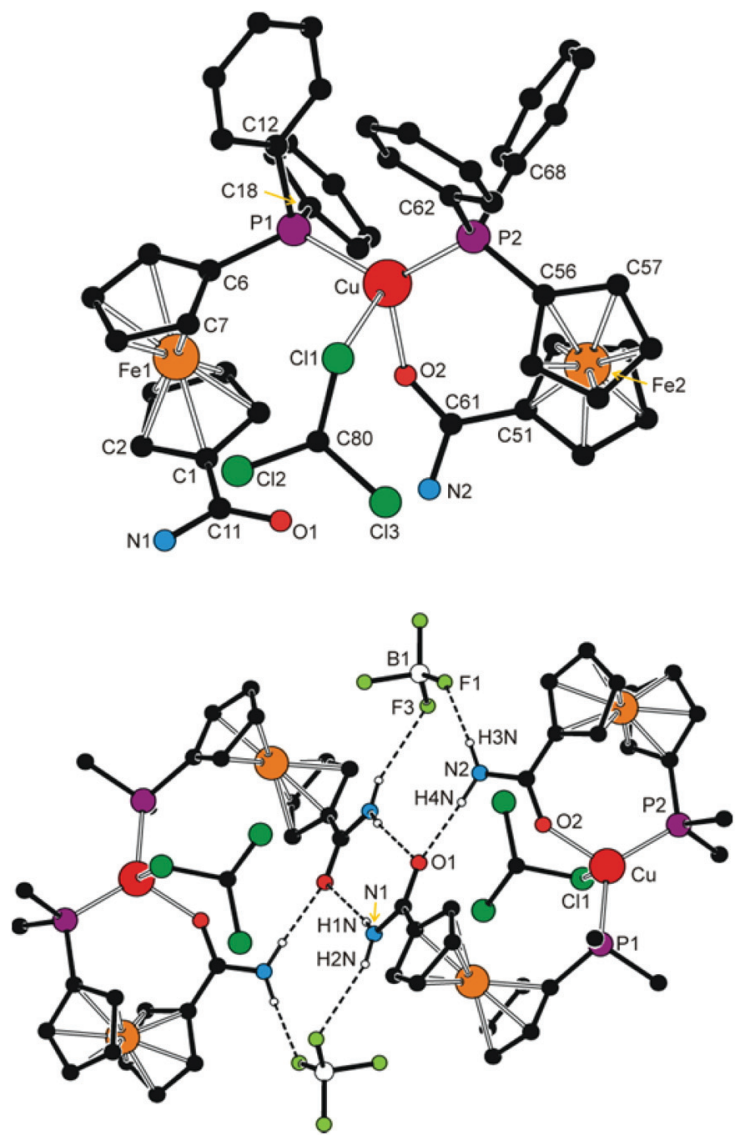

Fig. 9 Top: view of the complex molecule in the structure of $6 a^{\prime} \cdot \mathrm{CHCl}_{3}$. All $\mathrm{CH}$ hydrogen atoms are omitted for clarity. Bottom: packing diagram for $6 a^{\prime} \cdot \mathrm{CHCl}_{3}$. Only the pivotal carbon atoms from the phenyl rings and $\mathrm{NH}$ hydrogens are shown for clarity. Hydrogen bond parameters are as follows (in $\AA$ and ${ }^{\circ}$ ): $\mathrm{N} 1-\mathrm{H} 1 \mathrm{~N} \cdots \mathrm{O} 1, \mathrm{~N} 1 \ldots \mathrm{O} 1=2.914(5)$, angle at $\mathrm{H} 1 \mathrm{~N}=158 ; \mathrm{N} 1-\mathrm{H} 2 \mathrm{~N} \cdots \mathrm{F} 3, \mathrm{~N} 1 \cdots \mathrm{F} 3=3.15(1)$, angle at $\mathrm{H} 2 \mathrm{~N}=160$; $\mathrm{N} 2-\mathrm{H} 4 \mathrm{~N} \cdots \mathrm{O} 1, \mathrm{~N} 2 \cdots \mathrm{O} 1=2.914(4)$, angle at $\mathrm{H} 4 \mathrm{~N}=152 ; \mathrm{N} 2-\mathrm{H} 3 \mathrm{~N} \cdots \mathrm{F} 1$, $\mathrm{N} 2 \cdots \mathrm{F} 1=2.872(8)$, angle at $\mathrm{H} 3 \mathrm{~N}=152$.

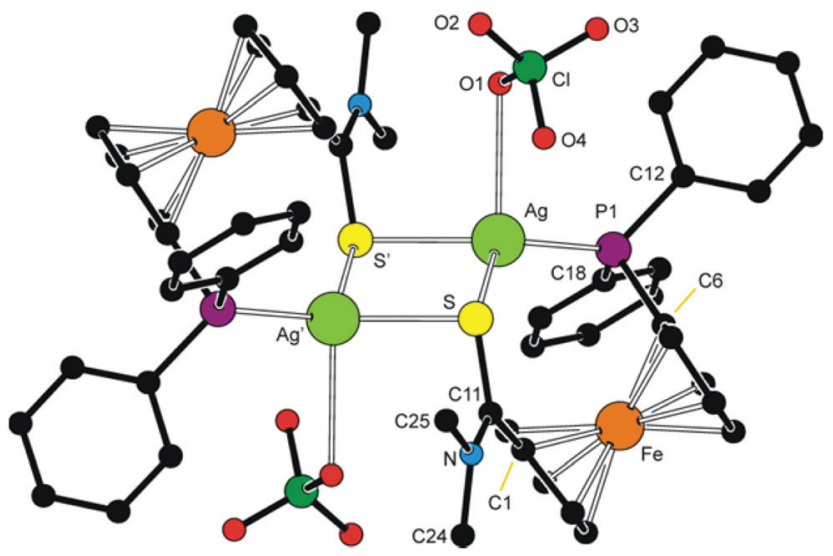

Fig. 10 View of the molecular structure of $7 \mathrm{~d}$. The prime-labelled atoms are generated by the crystallographic inversion.

chelating manner and are further involved in bridging of the "other" $\operatorname{Ag}(\mathrm{I})$ ion through the sulfur atom. The donor set around each $\mathrm{Ag}(\mathrm{I})$ is supplemented with an O-bonded perchlor-
Table 4 Selected distances and angles for 7d (in $\AA$ and $\left.{ }^{\circ}\right)^{a}$

\begin{tabular}{llll}
\hline $\mathrm{Ag}-\mathrm{P}$ & $2.426(1)$ & $\mathrm{P}-\mathrm{Ag}-\mathrm{S}$ & $121.68(4)$ \\
$\mathrm{Ag}-\mathrm{S}$ & $2.663(1)$ & $\mathrm{P}-\mathrm{Ag}-\mathrm{S}^{\prime}$ & $143.55(5)$ \\
$\mathrm{Ag}-\mathrm{S}^{\prime}$ & $2.572(1)$ & $\mathrm{P}-\mathrm{Ag}-\mathrm{O} 1$ & $95.9(1)$ \\
$\mathrm{Ag}-\mathrm{O} 1$ & $2.814(6)$ & $\mathrm{S}-\mathrm{Ag}-\mathrm{S}^{\prime}$ & $85.44(4)$ \\
$\mathrm{Ag} \cdots \mathrm{Ag}^{\prime}$ & $3.8469(7)$ & $\mathrm{S}-\mathrm{Ag}-\mathrm{O} 1$ & $117.6(1)$ \\
$\mathrm{S} \cdots \mathrm{S}^{\prime}$ & $3.552(2)$ & $\mathrm{S}-\mathrm{Ag}-\mathrm{O} 1$ & $90.9(1)$ \\
$\mathrm{Fe}-\mathrm{Cg} 1$ & $1.647(2)$ & $\angle \mathrm{Cp} 1, \mathrm{Cp} 2$ & $5.1(3)$ \\
$\mathrm{Fe}-\mathrm{Cg} 2$ & $1.651(2)$ & $\tau$ & $-80.9(3)$ \\
$\mathrm{C} 11=\mathrm{S}$ & $1.719(4)$ & $\mathrm{S}-\mathrm{C} 11-\mathrm{N}$ & $120.3(3)$ \\
$\mathrm{C} 11-\mathrm{N}$ & $1.306(6)$ & $\varphi$ & $37.8(5)$
\end{tabular}

${ }^{a}$ All parameters are defined as for the free ligand (see Table 1). The prime-labelled atoms are generated by the $(1-x, 2-y, 2-z)$ symmetry operation.

ate anion into a distorted tetrahedron. The $\mathrm{Ag}-\mathrm{O}$ distance of 2.814(6) $\AA$ falls well below the sum of the van der Waals radii (3.24 ̊), suggesting a relatively weaker yet significant interaction between the anion and $\mathrm{Ag}(\mathrm{I})$.

The $\mathrm{Ag}$-S distance pertaining to the sulfur atom from the chelating ligand is $c a .0 .1 \AA$ longer than the $\mathrm{Ag}-\mathrm{S}$ distance to the bridging sulfur, and the central $\mathrm{Ag}_{4} \mathrm{~S}_{4}$ ring has a twisted rhomboidal shape $\left(\mathrm{S}-\mathrm{Ag}-\mathrm{S}^{\prime}=85.44(4)^{\circ}, \mathrm{Ag}-\mathrm{S}-\mathrm{Ag}^{\prime}=94.56(4)^{\circ}\right)$. The ferrocene ligands adopt a conformation near to synclinal eclipsed (ideal value: $\tau=72^{\circ}$ ) and their amide pendants are twisted by $c a .38^{\circ}$.

\section{Synthesis of chloridogold(I) complexes}

For the sake of completeness, we have synthesised a series of chloridogold(I) complexes of the type $[\mathrm{AuCl}(\mathrm{L}-\mathrm{\kappa} P)](\mathbf{8} ; \mathrm{L}=\mathbf{2 - 5}$, Scheme 5), in which the amidophosphine ligands employ only their phosphorus donor moieties for coordination. These compounds were readily prepared via displacement of the tetrahydrothiophene (tht) ligand in $[\mathrm{AuCl}(\mathrm{tht})]$ by the stoichiometric amount of the respective amidophosphine, resulting in good to excellent yields depending on the isolation procedure.

Compounds 8a-d were characterised similarly to the $\mathrm{Cu}(\mathrm{I})$ and $\mathrm{Ag}(\mathrm{I})$ complexes discussed above. In addition, the molecular structure of $\mathbf{8 d}$ was determined by single-crystal X-ray diffraction analysis. The ${ }^{1} \mathrm{H}$ and ${ }^{31} \mathrm{P}\left\{{ }^{1} \mathrm{H}\right\}$ NMR spectra of 8a-d show signals of the phosphinoferrocene ligands and sharp singlets at $c a . \delta_{\mathrm{P}}+29$, respectively. The ESI MS spectra of these complexes display signals attributable to cationic fragments resulting from the loss of chloride ion $\left([\mathrm{M}-\mathrm{Cl}]^{+}\right)$and, for $\mathbf{8 a}-$ c, also the signals due to the pseudomolecular ions $\left([\mathrm{M}+\mathrm{Na}]^{+}\right.$ and $[\mathrm{M}+\mathrm{K}]^{+}$).

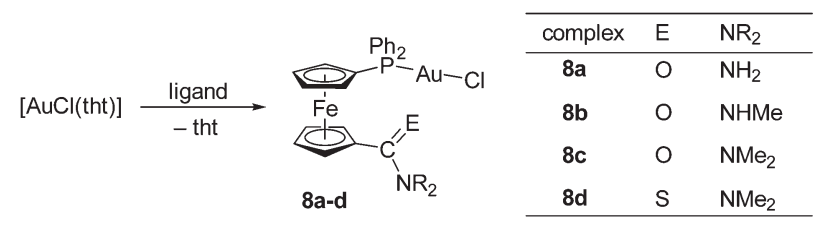

Scheme 5 Synthesis of $A u(1)$ complexes $8 a-d$ (tht $=$ tetrahydrothiophene). 


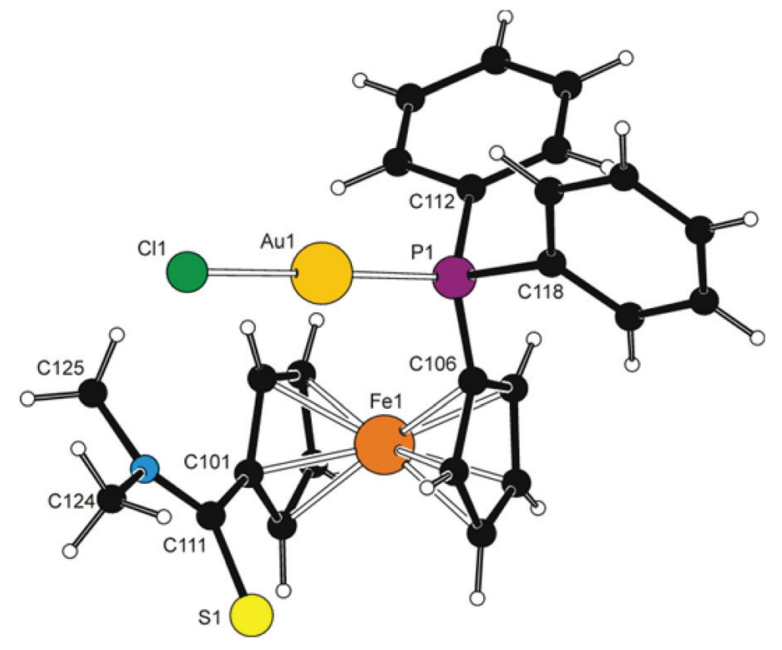

Fig. 11 View of molecule 1 in the crystal structure of $\mathbf{8 d}$. The labelling of molecule 2 is analogous with the respective labels having 2 as the first numeral. Selected distances and angles (in $\AA$ and ${ }^{\circ}$ ) for molecule 1 [molecule 2]: $\mathrm{Au}-\mathrm{Cl}$ 2.294(2) [2.278(2)], Au-P 2.230(2) [2.226(2)], $\mathrm{Cl}-$ $\mathrm{Au}-\mathrm{P}$ 178.3(1) [174.91(7)], Fe-Cg1 1.653(4) [1.654(4)], Fe-Cg2 1.640(3) [1.628(4)], $\tau-78.9(5)$ [-83.0(5)], $\mathrm{C}=\mathrm{S}$ 1.663(9) [1.669(8)], $\mathrm{C}-\mathrm{N}$ 1.34(1) [1.34(1)], S-C-N 123.2(6) [122.1(6)], $\varphi$ 33.2(8) [39.9(8)]. Note: the parameters are defined as for the free ligand.

\section{Molecular structure of $8 d$}

Complex 8d (Fig. 11) crystallises with two independent but otherwise similar ${ }^{36}$ molecules per asymmetric unit (for an overlap, see ESI $\dagger$ ). The molecules comprise the typical, practically linear $\mathrm{Cl}-\mathrm{Au}-\mathrm{P}$ moieties with the $\mathrm{Au}-\mathrm{P}$ and $\mathrm{Au}-\mathrm{Cl}$ bond lengths being close to those previously determined for $\left[\mathrm{AuCl}\left(\mathrm{FCPPh}_{2}\right)\right]^{37}$ and the related $\mathrm{AuCl}$ complexes with $1^{\prime}$-functionalised phosphinoferrocene ligands. ${ }^{38}$

The amidophosphine ligands in the two molecules exert negligible tilting on the ferrocene unit $\left(1.9(5)^{\circ}\right.$ and $\left.3.4(5)^{\circ}\right)$ and adopt conformations close to synclinal eclipsed ( $c f . \tau$ with the ideal value of $72^{\circ}$ ). The amide substituents are rotated by ca. $33^{\circ}$ and $40^{\circ}$ (for molecules $1 / 2$ ) from the planes of their parent cyclopentadienyl rings so that the bulky $\mathrm{NMe}_{2}$ unit are directed away from the ferrocene unit. The structure of $\mathbf{8 d}$ is essentially molecular; no $\mathrm{Au} \cdots \mathrm{Au}$ contacts indicative of possible aurophilic interactions ${ }^{39}$ were detected.

\section{Electrochemical study of representative complexes}

In addition to the characterization discussed above, complexes $\mathbf{6 c}, \mathbf{6 d}, \mathbf{7 c}$ and $\mathbf{8 c}$ as the representatives were studied by voltammetric methods similarly to the free ligands. Attention was paid mostly to the behaviour in the anodic region.

Thus, in cyclic voltammetry, compound $\mathbf{6 c}$ undergoes an oxidation which can be tentatively attributed to the oxidation of its ferrocene ligands (Fig. 12). However, the observed redox wave is composite, presumably owing to a convolution of two narrow-spaced oxidations (peak potentials: anodic $0.49 \mathrm{~V}$, cathodic $0.34 \mathrm{~V}$ ). This is clearly manifested in differential pulse voltammograms (see Figure in the ESI $\dagger$ ). The associated redox process appears to be reversible, though only when the

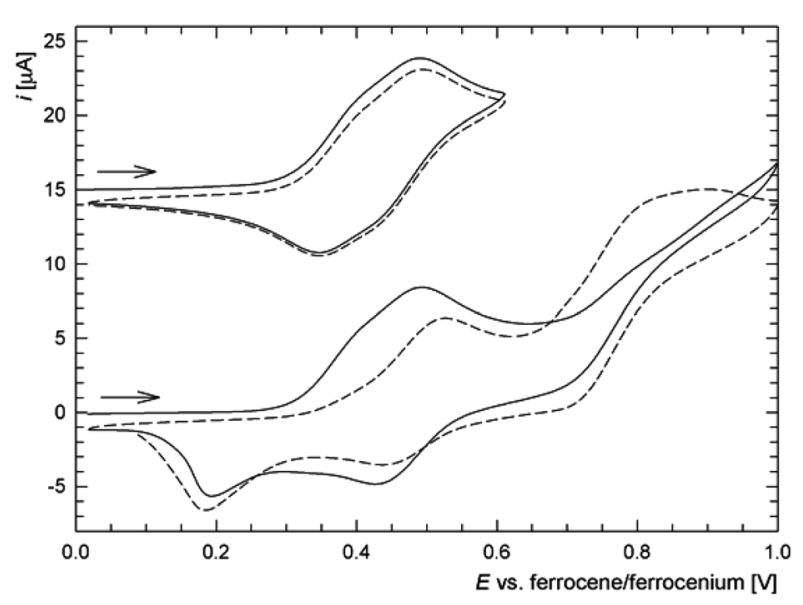

Fig. 12 Full (bottom) and partial (top) cyclic voltammograms of $6 \mathrm{c}$ as recorded at a glassy carbon electrode and with $0.1 \mathrm{~V} \mathrm{~s}^{-1}$ scan rate (second scans are shown as dashed lines). For clarity, the partial cyclic voltammogram is shifted by $+15 \mu \mathrm{A}$ (to avoid overlaps) and the scan direction is indicated with an arrow.

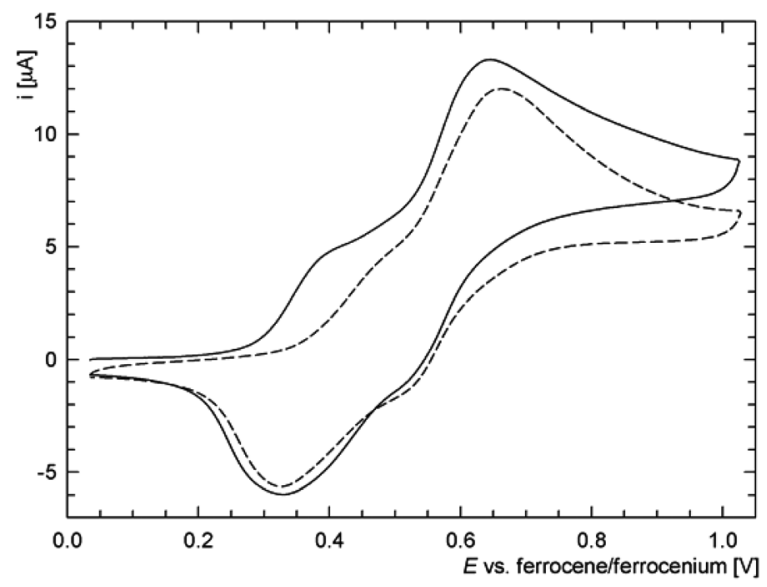

Fig. 13 Representative cyclic voltammograms of $6 \mathrm{~d}$ as recorded at a glassy carbon electrode and $0.1 \mathrm{~V} \mathrm{~s}^{-1}$ scan rate (the second scan is shown as a dashed line).

wave is scanned separate over a narrow range. If the scan is extended beyond this first redox event, an irreversible oxidative and two reduction waves appear, replacing the original redox response during the second and following scans (Fig. 12). The response of the analogous $\mathrm{Ag}(\mathrm{I})$ complex $7 \mathrm{c}$ in cyclic voltammetry is very similar (peak potentials for the composite wave: approx. 0.50 and $0.37 \mathrm{~V}$ ).

On the other hand, the redox behaviour of the $\mathrm{Cu}(\mathrm{I})$-thioamide complex $\mathbf{6 d}$ differs from that of $\mathbf{6 c}$ (Fig. 13) in that compound $6 \mathbf{d}$ undergoes an irreversible oxidation at $c a \cdot 0.41 \mathrm{~V}$ (peak potential). When the scan window is enlarged, a pair of redox waves appears at ca. 0.66 and $0.32 \mathrm{~V}$ that practically supersede the original oxidative wave. Finally, the gold(I) monophosphine complex 8c undergoes a standard one-electron oxidation at $E^{\circ}=0.375 \mathrm{~V}$. It is noteworthy that the wave, which can be ascribed to the ferrocene/ferrocenium couple, is 
electrochemically reversible, very likely because the lone pair at phosphorus as a reactive site is no longer available. ${ }^{5}$ The shift of the redox wave towards more positive potential with respect to free 2 corresponds with the expected electron density lowering at the ferrocene unit associated with coordination.

\section{Conclusions}

The results presented in this paper demonstrate that the reaction of 1'-(diphenylphosphino)-1-lithioferrocene with carbamoyl and thiocarbamoyl chlorides is a viable synthetic route to new phosphinoamide ligands, offering an alternative to other commonly employed preparative methods such as the amidation of carboxylic acids. The reaction appears to be particularly attractive for the synthesis of phosphine-thioamides because it eliminates the additional protection/deprotection steps required during the conventional thionations.

As evidenced by the structures of the free donors and their complexes, the molecules of 1 '-(diphenylphosphino)ferrocene amides and thioamides are flexible, allowing for a pre-organisation of the donor moieties into positions suitable for coordination via rotation of the ferrocene cyclopentadienyls and twisting of the amide unit around the pivotal $\mathrm{C}-\mathrm{C}$ bond at no substantial energy cost. The hybrid nature of these donors, particularly the amides combining hard and soft donor groups, results in hemilabile coordination in complexes with the soft Group 11 metal ions that in turn affects the stability and structural dynamics of these coordination compounds. The coordination variability is in no way reduced upon the replacement of amide oxygen with the soft sulfur atom. The thioamides may thus not only simply parallel the behaviour of their amide analogues but can also behave differently, taking advantage of the specific qualities of the thioamide moiety (longer $\mathrm{C}=\mathrm{S}$ bond, softer and less electronegative donor atom, etc.) and thus give rise to new and unique structural motifs ( $c f$. the structure of $\mathbf{7 d}$ ). All of these factors render the coordination chemistry of phosphino-thioamides an attractive research target that has not yet been explored in great detail.

\section{Experimental}

\section{Materials and methods}

All syntheses were performed under an argon atmosphere in the absence of direct daylight. Compounds $\mathbf{1}^{40}$ and [AuCl(tht) $]^{41}$ were synthesised according to the literature. Dichloromethane and tetrahydrofuran were dried with a Pure Solv MD-5 Solvent Purification System (Innovative Technology, USA). Benzene and toluene were dried over sodium metal and distilled under argon. Other chemicals and solvents utilised for crystallisations and during column chromatography were used as received (Sigma-Aldrich; solvents from Lachner, Czech Republic).
IR spectra were recorded with an FTIR Nicolet 760 instrument in the range $400-4000 \mathrm{~cm}^{-1}$. NMR spectra were obtained on a Varian UNITY Inova 400 spectrometer at $25{ }^{\circ} \mathrm{C}$ unless noted otherwise. Chemical shifts $(\delta / \mathrm{ppm})$ are referenced to internal tetramethylsilane (for ${ }^{1} \mathrm{H}$ and ${ }^{13} \mathrm{C}$ NMR spectra) and external $85 \%$ aqueous $\mathrm{H}_{3} \mathrm{PO}_{4}\left({ }^{31} \mathrm{P} \mathrm{NMR}\right.$ spectra). Alongside the standard notation of signal multiplicity, vq and vt are used to distinguish virtual quartets and triplets arising from the magnetically non-equivalent protons at the phosphine- and carbamoyl-substituted cyclopentadienyl rings, respectively.

Electrospray ionisation mass spectra (ESI MS) were recorded with a Bruker Esquire 3000 spectrometer using samples dissolved in HPLC-grade methanol. High-resolution (HR) ESI mass spectra were measured on a LTQ Orbitrap XL spectrometer. UV-vis spectra were recorded with a Unicam UV300 spectrometer in 1,2-dichloroethane. Elemental analyses were determined with a PE 2400 Series II CHNS/O Elemental Analyser (Perkin Elmer). The amount of clathrated solvent (if any) was verified by NMR analysis.

Safety note. Caution! Although we have not encountered any problems, it must be noted that perchlorate salts of complexes with organic ligands are potentially explosive and should be handled with care and only in small quantities.

\section{Synthesis of the amidophosphine ligands}

1'-(Diphenylphosphino)-1-[(dimethylamino)carbonyl]ferrocene (2). 1'-(Diphenylphosphino)-1-bromoferrocene $\quad(\mathbf{1} ; 0.90 \mathrm{~g}$, $2.0 \mathrm{mmol}$ ) was placed in a two-necked, round bottom flask and dissolved in dry tetrahydrofuran $(10 \mathrm{~mL})$. The orange solution was cooled for 10 minutes in a dry ice/ethanol bath before BuLi (1.0 mL of 2.5 M in hexanes, $2.5 \mathrm{mmol}$ ) was slowly introduced, causing the reaction mixture to darken. After stirring for $15 \mathrm{~min}$, neat $\mathrm{N}, \mathrm{N}$-dimethylcarbamoyl chloride $(0.39 \mathrm{~g}$, $3.6 \mathrm{mmol}$ ) was slowly added to the reaction mixture at $-78{ }^{\circ} \mathrm{C}$ and the stirring was continued at room temperature for 90 min. Saturated aqueous $\mathrm{NaHCO}_{3}$ (ca. $20 \mathrm{~mL}$ ) was introduced and the resulting mixture was stirred for an additional $15 \mathrm{~min}$. Then, the mixture was extracted with $\mathrm{Et}_{2} \mathrm{O}(3 \times 10 \mathrm{~mL})$, and the combined organic layers were washed with brine and dried over $\mathrm{MgSO}_{4}$. Following solvent removal, the crude product was purified by repeated column chromatography over silica gel using dichloromethane-methanol $(50: 1)$ and then ethyl acetate-hexane $(3: 1)$ as the eluents. Subsequent evaporation under vacuum afforded amide 2 as an orange solid. Yield: $0.41 \mathrm{~g}(46 \%)$.

${ }^{1} \mathrm{H}$ NMR (399.95 MHz, $\mathrm{CDCl}_{3}$ ): $\delta 3.04\left(\right.$ br s, $\left.6 \mathrm{H}, \mathrm{NMe}_{2}\right), 4.14$ (vq, $J^{\prime} \approx 1.7 \mathrm{~Hz}, 2 \mathrm{H}, \mathrm{fc}$ ), 4.19 (vt, $J^{\prime}=1.9 \mathrm{~Hz}, 2 \mathrm{H}, \mathrm{fc}$ ), 4.47 (vt, $\left.J^{\prime} \approx 1.9 \mathrm{~Hz}, 2 \mathrm{H}, \mathrm{fc}\right), 4.52\left(\mathrm{vt}, J^{\prime} \approx 1.9 \mathrm{~Hz}, 2 \mathrm{H}, \mathrm{fc}\right), 7.28-7.39(\mathrm{~m}$, $\left.10 \mathrm{H}, \mathrm{PPh}_{2}\right) .{ }^{31} \mathrm{P}\left\{{ }^{1} \mathrm{H}\right\}$ NMR (161.90 MHz, $\left.\mathrm{CDCl}_{3}\right): \delta-16.8(\mathrm{~s})$. ${ }^{13} \mathrm{C}\left\{{ }^{1} \mathrm{H}\right\}$ NMR (100.58 MHz, $\mathrm{CDCl}_{3}$ ): $\delta 37.5$ (very br, $\mathrm{NMe}_{2}$ ), 70.73 ( $\mathrm{CH}$ of fc), 71.44 ( $\mathrm{CH}$ of fc), 73.46 (d, $J_{\mathrm{PC}}=4 \mathrm{~Hz}, \mathrm{CH}$ of fc), $74.18\left(\mathrm{~d}, J_{\mathrm{PC}}=15 \mathrm{~Hz}, \mathrm{CH}\right.$ of fc), $79.20\left(C-\mathrm{CONMe}_{2}\right.$ of fc), $128.17\left(\mathrm{~d},{ }^{3} J_{\mathrm{PC}}=7 \mathrm{~Hz}, \mathrm{PPh}_{2} \mathrm{CH}_{\text {meta }}\right), 128.58\left(\mathrm{PPh}_{2} \mathrm{CH}_{\text {para }}\right)$, $133.43\left(\mathrm{~d},{ }^{2} J_{\mathrm{PC}}=20 \mathrm{~Hz}, \mathrm{PPh}_{2} \mathrm{CH}_{\text {ortho }}\right), 138.60\left(\mathrm{~d},{ }^{1} J_{\mathrm{PC}}=9 \mathrm{~Hz}\right.$, $\left.\mathrm{PPh}_{2} \mathrm{C}_{\text {ipso }}\right), 170.07(\mathrm{C}=\mathrm{O})$. The signal due to $C-\mathrm{PPh}_{2}$ was not observed. IR (Nujol): $\nu_{\max } 1615$ vs (amide I), 1502 s (amide II) 
$\mathrm{cm}^{-1}$. ESI+ MS: $m / z 442\left([\mathrm{M}+\mathrm{H}]^{+}\right)$. HR MS (ESI) calcd for $\mathrm{C}_{25} \mathrm{H}_{25}$ FeNOP $\left([\mathrm{M}+\mathrm{H}]^{+}\right)$442.1018, found 442.1019. Anal. Calcd for $\mathrm{C}_{25} \mathrm{H}_{24}$ FeNOP (441.3): C 68.04, N 3.17, H 5.48\%. Found: C 67.74, N 3.04, H 5.32\%.

1'-(Diphenylphosphino)-1-[(dimethylamino)thiocarbonyl]ferrocene (3). Thioamide 3 was prepared similarly to 2 using bromide 1 ( $0.90 \mathrm{~g}, 2.0 \mathrm{mmol})$ and $N, N$-dimethylthiocarbamoyl chloride (0.45 g, $3.6 \mathrm{mmol})$. An aqueous work-up as described above afforded an oily crude product, which was purified by column chromatography over silica gel using dichloromethane-methanol $(50: 1)$ and (in the second run) pure dichloromethane as the eluents. Following evaporation under vacuum, thioamide 3 was isolated as an a dark orange-red solid. Yield: $0.74 \mathrm{~g}, 81 \%$.

${ }^{1} \mathrm{H}$ NMR (399.95 MHz, $\mathrm{CDCl}_{3}$ ): $\delta 3.31$ (br s, $\left.3 \mathrm{H}, \mathrm{NMe}\right), 3.43$ (br s, $3 \mathrm{H}, \mathrm{NMe}$ ), 4.12 (vq, $J^{\prime} \approx 1.8 \mathrm{~Hz}, 2 \mathrm{H}, \mathrm{fc}$ ), 4.24 (vt, $J^{\prime} \approx 1.9 \mathrm{~Hz}, 2 \mathrm{H}, \mathrm{fc}$ ), 4.50 (vt, $J^{\prime} \approx 1.8 \mathrm{~Hz}, 2 \mathrm{H}, \mathrm{fc}$ ), 4.59 (vt, $\left.J^{\prime} \approx 1.9 \mathrm{~Hz}, 2 \mathrm{H}, \mathrm{fc}\right), 7.29-7.39\left(\mathrm{~m}, 10 \mathrm{H}, \mathrm{PPh}_{2}\right) .{ }^{31} \mathrm{P}\left\{{ }^{1} \mathrm{H}\right\} \mathrm{NMR}$ $\left(161.90 \mathrm{MHz}, \mathrm{CDCl}_{3}\right): \delta-16.8(\mathrm{~s}) .{ }^{13} \mathrm{C}\left\{{ }^{1} \mathrm{H}\right\} \mathrm{NMR}(100.58 \mathrm{MHz}$, $\mathrm{CDCl}_{3}$ ): $\delta 44.19$ (NMe), 45.08 (NMe), 70.62 ( $\mathrm{CH}$ of fc), 72.99 (CH of fc), 75.39 (d, $J_{\mathrm{PC}}=14 \mathrm{~Hz}, \mathrm{CH}$ of fc), $75.81\left(\mathrm{~d}, J_{\mathrm{PC}}=4 \mathrm{~Hz}\right.$, $\mathrm{CH}$ of fc), 88.02 (C-CSNMe ${ }_{2}$ of fc), 128.17 (d, ${ }^{3} J_{\mathrm{PC}}=7 \mathrm{~Hz}, \mathrm{PPh}_{2}$ $\left.\mathrm{CH}_{\text {meta }}\right), 128.57\left(\mathrm{PPh}_{2} \mathrm{CH}_{\text {para }}\right), 133.46\left(\mathrm{~d},{ }^{2} \mathrm{~J}_{\mathrm{PC}}=20 \mathrm{~Hz}, \mathrm{PPh}_{2}\right.$ $\left.\mathrm{CH}_{\text {ortho }}\right), 138.73\left(\mathrm{~d},{ }^{1} J_{\mathrm{PC}}=10 \mathrm{~Hz}, \mathrm{PPh}_{2} \mathrm{C}_{\text {ipso }}\right), 199.24(\mathrm{C}=\mathrm{S})$. The signal due to $C-\mathrm{PPh}_{2}$ was not observed. IR (Nujol): $\nu_{\max } 1508$ $\left(\nu_{\mathrm{C}-\mathrm{N}}\right) \mathrm{cm}^{-1}$. ESI+ MS: $m / z 480\left([\mathrm{M}+\mathrm{Na}]^{+}\right)$. HR MS (ESI) calcd for $\mathrm{C}_{25} \mathrm{H}_{25} \mathrm{NSPFe}([\mathrm{M}+\mathrm{H}])^{+} 458.0789$, found 458.0789.

1'-(Diphenylphosphino)-1-[(methylamino)carbonyl]ferrocene (4). Neat 1-[3-(dimethylamino)propyl]-3-ethylcarbodiimide (EDC; $0.40 \mathrm{~mL}, 2.4 \mathrm{mmol}$ ) was added to a mixture of 1'-(diphenylphosphino)ferrocene-1-carboxylic acid (Hdpf; $0.83 \mathrm{~g}$, $2.0 \mathrm{mmol})$, 1-hydroxybenzotriazole $(0.33 \mathrm{~g}, 2.40 \mathrm{mmol})$ and tetrahydrofuran $(5 \mathrm{~mL})$ while stirring and cooling in ice. After stirring at $0{ }^{\circ} \mathrm{C}$ for $30 \mathrm{~min}$, dimethylamine solution $(1.2 \mathrm{~mL}$ of $2 \mathrm{M}$ in THF, $2.4 \mathrm{mmol}$ ) was introduced and the resultant mixture was stirred at $0{ }^{\circ} \mathrm{C}$ for $30 \mathrm{~min}$ and then at room temperature overnight. The reaction was terminated by addition of a saturated aqueous $\mathrm{NaHCO}_{3}$ solution $(20 \mathrm{~mL})$ and stirring for additional $15 \mathrm{~min}$. The organic phase was separated and the aqueous layer was extracted with diethyl ether $(3 \times 10 \mathrm{~mL})$. The combined organic layers were washed with brine and dried over $\mathrm{MgSO}_{4}$. The crude product resulting after evaporation was purified by column chromatography on silica gel with dichloromethane-methanol $(20: 1)$ as the eluent. The first minor band was discarded and the second one was collected and evaporated to afford amide $\mathbf{4}$ as an orange yellow solid. Yield: $0.75 \mathrm{~g}, 87 \%$.

${ }^{1} \mathrm{H}$ NMR (399.95 MHz, $\left.\mathrm{CDCl}_{3}\right): \delta 2.83\left(\mathrm{~d},{ }^{3} J_{\mathrm{HH}}=4.9 \mathrm{~Hz}, 3 \mathrm{H}\right.$, $\mathrm{NMe}), 4.07$ (vq, $\left.J^{\prime} \approx 1.9 \mathrm{~Hz}, 2 \mathrm{H}, \mathrm{fc}\right), 4.22\left(\mathrm{vt}, J^{\prime} \approx 1.9 \mathrm{~Hz}, 2 \mathrm{H}\right.$, fc), 4.44 (vt, $J^{\prime} \approx 1.8 \mathrm{~Hz}, 2 \mathrm{H}, \mathrm{fc}$ ), 4.55 (vt, $J^{\prime} \approx 1.9 \mathrm{~Hz}, 2 \mathrm{H}, \mathrm{fc}$ ), $5.60\left(\mathrm{br} \mathrm{q},{ }^{3} J_{\mathrm{HH}} \approx 5 \mathrm{~Hz}, 1 \mathrm{H}, \mathrm{NH}\right), 7.31-7.41\left(\mathrm{~m}, 10 \mathrm{H}, \mathrm{PPh}_{2}\right)$. ${ }^{31} \mathrm{P}\left\{{ }^{1} \mathrm{H}\right\}$ NMR (161.90 MHz, $\left.\mathrm{CDCl}_{3}\right):-16.7$ (s). ${ }^{13} \mathrm{C}\left\{{ }^{1} \mathrm{H}\right\}$ NMR $\left(100.58 \mathrm{MHz}, \mathrm{CDCl}_{3}\right): \delta 26.50(\mathrm{NMe}), 69.38(\mathrm{CH}$ of fc), 71.31 (CH of fc), $72.71\left(\mathrm{~d}, J_{\mathrm{PC}}=4 \mathrm{~Hz}, \mathrm{CH}\right.$ of fc), $74.31\left(\mathrm{~d}, J_{\mathrm{PC}}=14 \mathrm{~Hz}\right.$, $\mathrm{CH}$ of fc), 128.30 (d, $\left.{ }^{3} J_{\mathrm{PC}}=7 \mathrm{~Hz}, \mathrm{PPh}_{2} \mathrm{CH}_{\text {meta }}\right), 128.80\left(\mathrm{PPh}_{2}\right.$ $\mathrm{CH}_{\text {para }}$ ), $133.48\left(\mathrm{~d},{ }^{2} J_{\mathrm{PC}}=20 \mathrm{~Hz}, \mathrm{PPh}_{2} \mathrm{CH}_{\text {ortho }}\right), 138.34\left(\mathrm{~d},{ }^{1} J_{\mathrm{PC}}=\right.$ $\left.9 \mathrm{~Hz}, \mathrm{PPh}_{2} \mathrm{C}_{\text {ipso }}\right), 170.30(\mathrm{C}=\mathrm{O})$. Signals due to ferrocene $\mathrm{C}_{\text {ipso }}$ were not observed. IR (Nujol): $\nu_{\max } 3308 \mathrm{~m}\left(\nu_{\mathrm{N}-\mathrm{H}}\right), 1628 \mathrm{~s}$ (amide I), $1545 \mathrm{~s}$ (amide II) $\mathrm{cm}^{-1}$. ESI+ MS: $m / z 428\left([\mathrm{M}+\mathrm{H}]^{+}\right)$. HR MS (ESI) calcd for $\mathrm{C}_{24} \mathrm{H}_{22} \mathrm{FeNNaOP}\left([\mathrm{M}+\mathrm{Na}]^{+}\right)$450.0681, found 450.0680. Anal. Calcd for $\mathrm{C}_{24} \mathrm{H}_{22} \mathrm{FeNO}$ (427.3): C 67.46, N 3.28, H 5.19\%. Found: C 67.07, N 3.24, H 5.03\%.

1'-(Diphenylphosphinyl)-1-[(methylamino)carbonyl]ferrocene (40). Aqueous hydrogen peroxide (2 drops of $30 \%$ solution) was added to a solution of amide 4 (48 $\mathrm{mg}, 0.11 \mathrm{mmol})$ in acetone $(8 \mathrm{~mL})$ while stirring and cooling in ice. The reaction mixture was stirred at $0{ }^{\circ} \mathrm{C}$ for $30 \mathrm{~min}$ and then diluted with water $(5 \mathrm{~mL})$. The organic solvent was removed under reduced pressure and the aqueous residue was extracted with dichloromethane $(3 \times 5 \mathrm{~mL})$. The organic washings were combined, dried over $\mathrm{MgSO}_{4}$ and evaporated. The residue was dissolved in dichloromethane $(2 \mathrm{~mL})$ and the solution was passed through a plug of silica gel eluted with dichloromethanemethanol (10:1). Following evaporation, phosphine oxide 40 was isolated as a dark yellow solid. Yield: $40 \mathrm{mg}, 82 \%$.

${ }^{1} \mathrm{H}$ NMR (399.95 MHz, $\left.\mathrm{CDCl}_{3}\right): \delta 2.93\left(\mathrm{~d},{ }^{3} \mathrm{~J}_{\mathrm{HH}}=4.7 \mathrm{~Hz}, 3 \mathrm{H}\right.$, $\mathrm{NMe}$ ), 4.07 (vt, $\left.J^{\prime} \approx 1.9 \mathrm{~Hz}, 2 \mathrm{H}, \mathrm{fc}\right), 4.14\left(\mathrm{vq}, J^{\prime} \approx 1.9 \mathrm{~Hz}, 2 \mathrm{H}\right.$, $\mathrm{fc}), 4.58$ (vq, $J^{\prime} \approx 1.8 \mathrm{~Hz}, 2 \mathrm{H}, \mathrm{fc}$ ), 4.99 (vt, $J^{\prime} \approx 1.9 \mathrm{~Hz}, 2 \mathrm{H}, \mathrm{fc}$ ), 7.44-7.58 (m, $6 \mathrm{H}, \mathrm{PPh}_{2}$ ), 7.65-7.73 (m, $4 \mathrm{H}, \mathrm{PPh}_{2}$ ), 8.76 (br q, ${ }^{3} J_{\mathrm{HH}}$ ca. $\left.4.5 \mathrm{~Hz}, 1 \mathrm{H}, \mathrm{NH}\right) .{ }^{31} \mathrm{P}\left\{{ }^{1} \mathrm{H}\right\} \mathrm{NMR}\left(161.90 \mathrm{MHz}, \mathrm{CDCl}_{3}\right)$ : $\delta 31.6(\mathrm{~s}) .{ }^{13} \mathrm{C}\left\{{ }^{1} \mathrm{H}\right\}$ NMR (100.58 $\left.\mathrm{MHz}, \mathrm{CDCl}_{3}\right): \delta 26.46(\mathrm{NMe})$, 70.26 ( $\mathrm{CH}$ of fc), 70.74 ( $\mathrm{CH}$ of fc), $72.56\left(\mathrm{~d}, J_{\mathrm{PC}}=11 \mathrm{~Hz}, \mathrm{CH}\right.$ of fc), 73.07 (d, ${ }^{1} J_{\mathrm{PC}}=114 \mathrm{~Hz}, C-\mathrm{PPh}_{2}$ of fc), $74.91\left(\mathrm{~d}, J_{\mathrm{PC}}=13 \mathrm{~Hz}\right.$, $\mathrm{CH}$ of fc), 79.63 (C-CONH of fc), 128.45 (d, $J_{\mathrm{PC}}=12 \mathrm{~Hz}, \mathrm{PPh}_{2}$ $\mathrm{CH}), 131.43\left(\mathrm{~d}, J_{\mathrm{PC}}=10 \mathrm{~Hz}, \mathrm{PPh}_{2} \mathrm{CH}\right), 131.94\left(\mathrm{~d},{ }^{4} J_{\mathrm{PC}}=2 \mathrm{~Hz}\right.$, $\mathrm{PPh}_{2} \mathrm{CH}_{\text {para }}$ ), $133.10\left(\mathrm{~d},{ }^{1} J_{\mathrm{PC}}=108 \mathrm{~Hz}, \mathrm{PPh}_{2} \mathrm{C}_{\text {ipso }}\right.$ ), 170.35 $(\mathrm{C}=\mathrm{O})$. IR (Nujol): $\nu_{\max } 3246 \mathrm{~m}, 1657 \mathrm{~s}$ (amide I), $1556 \mathrm{~s}$ (amide II) $\mathrm{cm}^{-1}$. ESI+ MS: $m / z 466\left([\mathrm{M}+\mathrm{Na}]^{+}\right)$. HR MS (ESI) calcd for $\mathrm{C}_{24} \mathrm{H}_{23} \mathrm{FeNO}_{2} \mathrm{P}\left([\mathrm{M}+\mathrm{H}]^{+}\right)$444.0810, found 444.0809. Anal. Calcd for $\mathrm{C}_{24} \mathrm{H}_{22} \mathrm{FeNO}_{2} \cdot 1 / 4 \mathrm{CH}_{2} \mathrm{Cl}_{2}$ (464.5): $\mathrm{C} 62.71, \mathrm{~N}$ 3.02 , H 4.88\%. Found: C 62.70, N 2.81, H 4.73\%.

1'-(Diphenylphosphinothioyl)-1-[(methylamino)carbonyl]ferrocene (4S). Amide $4(61 \mathrm{mg}, 0.14 \mathrm{mmol})$ and elemental sulfur $(5.0 \mathrm{mg}, 0.16 \mathrm{mmol})$ were dissolved in dry toluene (5 mL) and the resulting solution was heated at $80^{\circ} \mathrm{C}$ for 90 min. Subsequent evaporation afforded a yellow brown residue, which was taken up with dichloromethane $(2 \mathrm{~mL})$ and filtered through a plug of silica gel eluted with dichloromethane-methanol $(50: 1)$. Subsequent evaporation afforded the product as a yellow glassy solid. Yield of $4 \mathrm{~S}: 40 \mathrm{mg}, 62 \%$.

${ }^{1} \mathrm{H}$ NMR (399.95 MHz, $\left.\mathrm{CDCl}_{3}\right): \delta 2.92\left(\mathrm{~d},{ }^{3} J_{\mathrm{HH}}=4.8 \mathrm{~Hz}, 3 \mathrm{H}\right.$, $\mathrm{NMe}$ ), 3.96 (vt, $J^{\prime} \approx 2.0 \mathrm{~Hz}, 2 \mathrm{H}, \mathrm{fc}$ ), 4.23 (vq, $J^{\prime} \approx 2.0 \mathrm{~Hz}, 2 \mathrm{H}$, $\mathrm{fc}), 4.62\left(\mathrm{vq}, J^{\prime} \approx 2.0 \mathrm{~Hz}, 2 \mathrm{H}, \mathrm{fc}\right), 4.90$ (vt, $J^{\prime} \approx 2.0 \mathrm{~Hz}, 2 \mathrm{H}, \mathrm{fc}$ ), 7.41 (br q, $\left.{ }^{3} J_{\mathrm{HH}} \approx 5 \mathrm{~Hz}, 1 \mathrm{H}, \mathrm{NH}\right), 7.43-7.56\left(\mathrm{~m}, 6 \mathrm{H}, \mathrm{PPh}_{2}\right)$, 7.68-7.76 (m, $\left.4 \mathrm{H}, \mathrm{PPh}_{2}\right) .{ }^{31} \mathrm{P}\left\{{ }^{1} \mathrm{H}\right\} \mathrm{NMR}\left(161.90 \mathrm{MHz}, \mathrm{CDCl}_{3}\right)$ : $\delta 42.9$ (s). ${ }^{13} \mathrm{C}\left\{{ }^{1} \mathrm{H}\right\}$ NMR (100.58 MHz, $\mathrm{CDCl}_{3}$ ): $\delta 26.13$ (NMe), 70.86 ( $\mathrm{CH}$ of fc), 71.00 ( $\mathrm{CH}$ of fc), 73.05 (d, $J_{\mathrm{PC}}=10 \mathrm{~Hz}, \mathrm{CH}$ of fc), $74.81\left(\mathrm{~d}, J_{\mathrm{PC}}=12 \mathrm{~Hz}, \mathrm{CH}\right.$ of fc), $75.98\left(\mathrm{~d},{ }^{1} J_{\mathrm{PC}}=97 \mathrm{~Hz}\right.$, $C-\mathrm{PPh}_{2}$ of fc), 79.01 (C-CONH of fc), 128.40 (d, $J_{\mathrm{PC}}=13 \mathrm{~Hz}$, $\mathrm{PPh}_{2} \mathrm{CH}$ ), 131.60 (d, $\left.J_{\mathrm{PC}}=10 \mathrm{~Hz}, \mathrm{PPh}_{2} \mathrm{CH}\right), 131.62\left(\mathrm{~d},{ }^{4} J_{\mathrm{PC}}=\right.$ $4 \mathrm{~Hz}, \mathrm{PPh}_{2} \mathrm{CH}_{\text {para }}$ ), 133.51 (d, ${ }^{1} J_{\mathrm{PC}}=88 \mathrm{~Hz}, \mathrm{PPh}_{2} \mathrm{C}_{\text {ipso }}$ ), 169.88 $(\mathrm{C}=\mathrm{O})$. IR (Nujol): $\nu_{\max } 3298 \mathrm{~m}, 3229 \mathrm{~m}, 1628 \mathrm{~s}$ (amide I), 
$1558 \mathrm{~s}$ (amide II) $\mathrm{cm}^{-1}$. ESI+ MS: $m / z 482\left([\mathrm{M}+\mathrm{Na}]^{+}\right)$. HR MS (ESI) calcd for $\mathrm{C}_{24} \mathrm{H}_{23} \mathrm{FeNOPS}\left([\mathrm{M}+\mathrm{H}]^{+}\right)$460.0582, found 460.0583. Anal. Calcd for $\mathrm{C}_{24} \mathrm{H}_{22}$ FeNOPS $1 / 2 \mathrm{CH}_{2} \mathrm{Cl}_{2}$ (501.2): C 58.64, N 2.79, H 4.62\%. Found C 58.57, N 2.71, H 4.53\%.

\section{Synthesis of $\mathrm{Cu}(\mathrm{I})$ complexes}

$\left[\mathbf{C u}(7-\kappa P)_{2}\right]\left[\mathrm{BF}_{4}\right]$ (6a). 1'-(Diphenylphosphino)-1-(aminocarbonyl)ferrocene $(5 ; 80 \mathrm{mg}, 0.19 \mathrm{mmol})$ and $\left[\mathrm{Cu}(\mathrm{MeCN})_{4}\right]\left[\mathrm{BF}_{4}\right]$ (29 $\mathrm{mg}, 0.092 \mathrm{mmol}$ ) were dissolved in dry dichloromethane $(2 \mathrm{~mL})$, and the resulting orange solution was stirred for $4 \mathrm{~h}$ at room temperature in the dark. The separated solid was filtered off, washed with pentane and dried under vacuum. Yield: $84 \mathrm{mg}$ (93\%), yellow solid.

${ }^{1} \mathrm{H}$ NMR (399.95 MHz, dmso-d ${ }_{6}$ ): $\delta 4.15$ (br s, $2 \mathrm{H}, \mathrm{fc}$ ), 4.19 (vt, $2 \mathrm{H}, J^{\prime}=1.7 \mathrm{~Hz}, \mathrm{fc}$ ), 4.51 (vt, $2 \mathrm{H}, J^{\prime}=1.7 \mathrm{~Hz}, \mathrm{fc}$ ), 4.82 (br s, $2 \mathrm{H}, \mathrm{fc}), 7.40\left(\mathrm{~s}, 1 \mathrm{H}, \mathrm{NH}_{2}\right), 7.42-7.52\left(\mathrm{~m}, 10 \mathrm{H}, \mathrm{PPh}_{2}\right), 7.71(\mathrm{~s}, 1$ $\left.\mathrm{H}, \mathrm{NH}_{2}\right) .{ }^{31} \mathrm{P}\left\{{ }^{1} \mathrm{H}\right\}\left(161.90 \mathrm{MHz}\right.$, dmso-d $\left._{6}\right): \delta-10.1$ (br s). IR (Nujol): $\nu_{\max } 3450(\mathrm{~m}), 3362$ (m), 1650 (s) 1583 (s), 1481 (m), 1437 (m), 1405 (m), 1167 (m), 1095 (s), 1069 (s), 1029 (s), 837 (m), $748(\mathrm{~m}), 697(\mathrm{~m}), 517(\mathrm{~m}), 502(\mathrm{~m}) \mathrm{cm}^{-1}$. ESI+ MS: $m / z 889$ $\left(\left[\mathrm{Cu}(5)_{2}\right]^{+}\right), 476\left([\mathrm{Cu}(5)]^{+}\right)$. Anal. calcd for $\mathrm{C}_{46} \mathrm{H}_{40} \mathrm{BCuF}_{4} \mathrm{Fe}_{2}-$ $\mathrm{N}_{2} \mathrm{O}_{2} \mathrm{P}_{2} \cdot 1 / 2 \mathrm{CH}_{2} \mathrm{Cl}_{2}$ (1019.3): C 54.79; N 2.75, H 4.05\%. Found C 54.51; N 3.00, H 4.27\%.

$\left[\mathbf{C u}(\mathbf{4}-\boldsymbol{\kappa} \boldsymbol{P})_{2}\right]\left[\mathbf{B F}_{4}\right]$ (6b). Amide $4(60 \mathrm{mg}, 0.14 \mathrm{mmol})$ and $\left[\mathrm{Cu}(\mathrm{MeCN})_{4}\right]\left[\mathrm{BF}_{4}\right](22 \mathrm{mg}, 0.070 \mathrm{mmol})$ were dissolved in dry dichloromethane $(3 \mathrm{~mL})$. The resulting yellow solution was stirred at room temperature for $18 \mathrm{~h}$, filtered through a PTFE syringe filter $(0.45 \mu \mathrm{m}$ pore size), and the filtrate was precipitated by addition of pentane $(4 \mathrm{~mL})$. The yellow precipitate was filtered off, washed with pentane and dried under vacuum. Yield: $44 \mathrm{mg}$ (63\%), yellow powder.

${ }^{1} \mathrm{H}$ NMR (399.95 MHz, dmso-d 6 ): $\delta 2.73\left(\mathrm{~d},{ }^{3} J_{\mathrm{HH}}=4.5 \mathrm{~Hz}\right.$, $3 \mathrm{H}, \mathrm{NMe}$ ), 4.15 (vt, $J^{\prime}=1.8 \mathrm{~Hz}, 2 \mathrm{H}, \mathrm{fc}$ ), 4.18 (vt, $J^{\prime}=1.8 \mathrm{~Hz}$, $2 \mathrm{H}, \mathrm{fc}$ ), 4.52 (vt, $J^{\prime}=1.8 \mathrm{~Hz}, 2 \mathrm{H}, \mathrm{fc}$ ), 4.75 (vt, $J^{\prime}=1.8 \mathrm{~Hz}, 2 \mathrm{H}$, fc), 7.38-7.50 (m, $\left.10 \mathrm{H}, \mathrm{PPh}_{2}\right), 8.24\left(\mathrm{br} \mathrm{d},{ }^{3} J_{\mathrm{HH}} \approx 4.5 \mathrm{~Hz}, 1 \mathrm{H}\right.$, NH). ${ }^{31} \mathrm{P}\left\{{ }^{1} \mathrm{H}\right\}$ NMR (161.90 MHz, dmso-d ${ }_{6}$ ): $\delta-11.5$ (br s). IR (Nujol): $\nu 3397$ (m), 1618 (s), 1601 (w), 1558 (s), 1435 (m), 1411 (m), 1310 (m), 1165 (w), 1061 (s), 1029 (s), 830 (m), 816 (m), 747 (s), 699 (s), 519 (s), $510(\mathrm{~m}), 488(\mathrm{~s}), 462(\mathrm{~m}) \mathrm{cm}^{-1}$. ESI+ MS: $m / z \quad 917\left(\left[\mathrm{Cu}(\mathbf{4})_{2}\right]^{+}\right), 490\left([\mathrm{Cu}(4)]^{+}\right)$. Anal. Calcd for $\mathrm{C}_{48} \mathrm{H}_{44} \mathrm{BCuF}_{4} \mathrm{Fe}_{2} \mathrm{~N}_{2} \mathrm{O}_{2} \mathrm{P}_{2} \cdot \mathrm{CH}_{2} \mathrm{Cl}_{2}$ (1089.8): C 54.00, $\mathrm{N}$ 2.57, $\mathrm{H} 4.25 \%$. Found C 54.28, N 2.47, H 4.20\%.

$\left[\mathbf{C u}(2-\kappa P)_{2}\right]\left[\mathrm{BF}_{4}\right]$ (6c). Complex $6 \mathrm{c}$ was prepared similarly starting with amide $2(50 \mathrm{mg}, 0.11 \mathrm{mmol})$ and $\left[\mathrm{Cu}(\mathrm{MeCN})_{4}\right]$ $\left[\mathrm{BF}_{4}\right](18 \mathrm{mg}, 0.057 \mathrm{mmol})$ in $2 \mathrm{~mL}$ of dichloromethane. The reaction mixture was stirred for only $4 \mathrm{~h}$ prior to the filtration and precipitation. Yield: $44 \mathrm{mg}(75 \%)$, fine yellow powder.

${ }^{1} \mathrm{H}$ NMR (399.95 MHz, dmso-d ${ }_{6}$ ): $\delta 2.93$ (br s, $3 \mathrm{H}, \mathrm{NMe}$ ), 3.02 (br s, $3 \mathrm{H}, \mathrm{NMe}$ ), 4.19 (vt, $J^{\prime}=1.8 \mathrm{~Hz}, 2 \mathrm{H}, \mathrm{fc}$ ), 4.21 (vt, $J^{\prime}=$ $1.8 \mathrm{~Hz}, 2 \mathrm{H}, \mathrm{fc}$ ), 4.53 (br s, $2 \mathrm{H}, \mathrm{fc}$ ), 4.60 (vt, J' = $1.8 \mathrm{~Hz}, 2 \mathrm{H}, \mathrm{fc}$ ), 7.42-7.53 (m, $\left.10 \mathrm{H}, \mathrm{PPh}_{2}\right) .{ }^{31} \mathrm{P}\left\{{ }^{1} \mathrm{H}\right\}$ NMR (161.90 MHz, dmso$\mathrm{d}_{6}$ ): $\delta-10.5$ (br s). IR (Nujol): $\nu_{\max } 1582$ (s), 1575 (s), 1505, (m), 1435 (w), 1401 (m), 1377 (m), 1112 (m), 1096 (m), 1050 (s) 1032 (s), $745(\mathrm{~m}), 696(\mathrm{~s}), 511(\mathrm{~s}), 495(\mathrm{~s}) \mathrm{cm}^{-1}$. ESI+ MS: $\mathrm{m} / \mathrm{z} 945$ $\left(\left[\mathrm{Cu}(2)_{2}\right]^{+}\right), 504\left([\mathrm{Cu}(2)]^{+}\right)$. Anal. calcd for $\mathrm{C}_{50} \mathrm{H}_{48} \mathrm{BCuF}_{4} \mathrm{Fe}_{2}{ }^{-}$
$\mathrm{N}_{2} \mathrm{O}_{2} \mathrm{P}_{2}$ (1032.9): C 58.14, N 2.71; H 4.68\%. Found: C 58.63, N 2.52, H $4.94 \%$.

$\left[\mathbf{C u}(3-\kappa P)_{2}\right]\left[\mathbf{B F}_{4}\right](\mathbf{6 d})$. Compound $\mathbf{6 d}$ was prepared and isolated analogously to $\mathbf{6 c}$ using thioamide 3 (38 $\mathrm{mg}$, $0.083 \mathrm{mmol})$ and $\left[\mathrm{Cu}(\mathrm{MeCN})_{4}\right]\left[\mathrm{BF}_{4}\right](13 \mathrm{mg}, 0.041 \mathrm{mmol})$ as the starting materials. Yield of $\mathbf{6 d}: 38 \mathrm{mg}(87 \%)$, orange solid.

${ }^{1} \mathrm{H}$ NMR (399.95 MHz, dmso-d $\left.{ }_{6}, 25{ }^{\circ} \mathrm{C}\right): \delta 3.28$ (br s, $3 \mathrm{H}$, NMe), 3.53 (s, $3 \mathrm{H}, \mathrm{NMe}$ ), 4.15 (br s, $2 \mathrm{H}, \mathrm{fc}$ ), 4.35 (br s, $2 \mathrm{H}$, fc), 4.60 (br s, $2 \mathrm{H}, \mathrm{fc}$ ), 4.64 (br s, $2 \mathrm{H}, \mathrm{fc}), 7.30-7.52(\mathrm{~m}, 10 \mathrm{H}$, $\mathrm{PPh}_{2}$ ). ${ }^{1} \mathrm{H}$ NMR (399.95 MHz, dmso-d $\left.{ }_{6}, 50{ }^{\circ} \mathrm{C}\right): \delta 3.19(\mathrm{~s}, 3 \mathrm{H}$, $\mathrm{NMe}$ ), 3.53 (s, $3 \mathrm{H}, \mathrm{NMe}$ ), 4.16 (br s, $2 \mathrm{H}, \mathrm{fc}$ ), 4.35 (vt, $J^{\prime}=$ $1.9 \mathrm{~Hz}, 2 \mathrm{H}, \mathrm{fc}$ ), 4.59 (vt, $J^{\prime}=1.9 \mathrm{~Hz}, 2 \mathrm{H}, \mathrm{fc}$ ), 4.74 (br s, $2 \mathrm{H}, \mathrm{fc}$ ), 7.35-7.50 (m, $\left.10 \mathrm{H}, \mathrm{PPh}_{2}\right) .{ }^{31} \mathrm{P}\left\{{ }^{1} \mathrm{H}\right\}$ NMR (161.90 MHz, dmso$\mathrm{d}_{6}, 25{ }^{\circ} \mathrm{C}$ ): $\delta-11.0$ (br s). IR (Nujol): $\nu_{\max } 1712(\mathrm{w}), 1526(\mathrm{~m})$, 1436 (w), 1277 (m), 1059 (s) 1135 (m), 825 (m) 745 (m), 697 (m), $511(\mathrm{~m}), 491(\mathrm{w}) \mathrm{cm}^{-1}$. ESI+ MS: m/z $977\left(\left[\mathrm{Cu}(3)_{2}\right]^{+}\right), 520$ $\left([\mathrm{Cu}(3)]^{+}\right)$. Anal. Calcd for $\mathrm{C}_{50} \mathrm{H}_{48} \mathrm{BCuF}_{4} \mathrm{Fe}_{2} \mathrm{~N}_{2} \mathrm{P}_{2} \mathrm{~S}_{2} \cdot 1 / 4 \mathrm{CH}_{2} \mathrm{Cl}_{2}$ (1086.3): C 55.56, N 2.58, H 4.50\%. Found: C 55.53, N 2.57, H $4.77 \%$.

\section{Synthesis of $\mathbf{A g}(\mathrm{I})$ complexes}

$\left[\mathbf{A g}(7-\kappa P)_{2}\right] \mathbf{C l O}_{4}$ (7a). A solution of silver(I) perchlorate $(6.0 \mathrm{mg}, 0.029 \mathrm{mmol})$ in dry benzene $(2 \mathrm{~mL})$ was added to solid amide 5 (25 mg, $0.061 \mathrm{mmol}$ ) and the resultant mixture was diluted with dry dichloromethane $(4 \mathrm{~mL})$. The reaction mixture was stirred at room temperature for $4 \mathrm{~h}$, whereupon it deposited a light orange solid, which was filtered off, washed with pentane and dried under vacuum. Yield of 7a: $28 \mathrm{mg}$ (87\%), light orange powder.

${ }^{1} \mathrm{H}$ NMR (399.95 $\mathrm{MHz} \mathrm{CDCl}_{3}$ ): $\delta 4.11$ (br vt, $J^{\prime}=1.9 \mathrm{~Hz}, 2 \mathrm{H}$, fc), 4.46 (br s, $2 \mathrm{H}, \mathrm{fc}$ ), 4.72 (vt, $J^{\prime}=1.9 \mathrm{~Hz}, 2 \mathrm{H}, \mathrm{fc}$ ), 4.84 (br vt, $\left.J^{\prime}=1.8 \mathrm{~Hz}, 2 \mathrm{H}, \mathrm{fc}\right), 6.24$ (br s, $\left.1 \mathrm{H}, \mathrm{NH}\right), 6.75$ (br s, $1 \mathrm{H}, \mathrm{NH}$ ), 7.39-7.56 (m, $\left.10 \mathrm{H}, \mathrm{PPh}_{2}\right) .{ }^{31} \mathrm{P}\left\{{ }^{1} \mathrm{H}\right\} \mathrm{NMR}\left(161.90 \mathrm{MHz}, \mathrm{CDCl}_{3}\right)$ : $\delta 3.1$ (broad d, ${ }^{1} J\left({ }^{107 / 109} \mathrm{Ag},{ }^{31} \mathrm{P}\right) \approx 510 \mathrm{~Hz}$ ). IR (Nujol): $\nu_{\max }$ 3444 (m), 3340 (m), 1645 (s), 1591 (s), 1555 (m), 1479 (w), 1436 (s), 1396 (m), 1168 (m), 1098 (br s), 1027 (s), 910 (m), 837 (m), 826 (m), 747 (s), 735 (s), 697 (s), 624 (m), 532 (w), 506 (s), 489 $(\mathrm{m}), 465(\mathrm{~m}) \mathrm{cm}^{-1}$. ESI+ MS: $\mathrm{m} / z 933\left(\left[\mathrm{Ag}(5)_{2}\right]^{+}\right), 520\left([\operatorname{Ag}(5)]^{+}\right)$. Anal. Calc. for $\mathrm{C}_{46} \mathrm{H}_{40} \mathrm{Ag} \cdot \mathrm{ClFe}_{2} \mathrm{~N}_{2} \mathrm{O}_{6} \mathrm{P}_{2} \cdot \mathrm{CH}_{2} \mathrm{Cl}_{2}$ (1118.7): C 50.46, H 3.76, N 2.50\%. Found: C 49.95, H 3.58, N 2.62\%.

$\left[\mathbf{A g}(\mathbf{4}-\boldsymbol{\kappa} \boldsymbol{P})_{2}\right] \mathbf{C l O}_{4}(7 \mathbf{b})$. Amide $4(26 \mathrm{mg}, 0.061 \mathrm{mmol})$ and $\mathrm{AgClO}_{4}(6.0 \mathrm{mg}, 0.029 \mathrm{mmol})$ were reacted in a mixture of benzene $(1 \mathrm{~mL})$ and dichloromethane $(3 \mathrm{~mL})$ for $20 \mathrm{~h}$ as described above. The yellow solid that formed was filtered off, washed with $\mathrm{Et}_{2} \mathrm{O}$ and dried under vacuum to give $7 \mathbf{b}$ as a yellow powder (26 mg, 78\%).

${ }^{1} \mathrm{H}$ NMR (399.95 MHz, dmso-d $): \delta 2.67\left(\mathrm{~d},{ }^{3} J_{\mathrm{HH}}=4.6 \mathrm{~Hz}\right.$, $3 \mathrm{H}, \mathrm{NMe}$ ), 4.12 (vt, $J^{\prime}=1.9 \mathrm{~Hz}, 2 \mathrm{H}, \mathrm{fc}$ ), 4.29 (vt, $J^{\prime}=1.9 \mathrm{~Hz}$, $2 \mathrm{H}, \mathrm{fc}$ ), 4.60 (vt, $J^{\prime}=1.9 \mathrm{~Hz}, 2 \mathrm{H}, \mathrm{fc}$ ), 4.85 (vt, $J^{\prime}=1.9 \mathrm{~Hz}, 2 \mathrm{H}$, fc), 7.44-7.60 (m, $\left.10 \mathrm{H}, \mathrm{PPh}_{2}\right), 8.09\left(\mathrm{q},{ }^{3} J_{\mathrm{HH}}=4.6 \mathrm{~Hz}, 1 \mathrm{H}, \mathrm{NH}\right)$. ${ }^{31} \mathrm{P}\left\{{ }^{1} \mathrm{H}\right\}$ NMR (161.90 MHz, dmso-d ${ }_{6}$ ): $\delta 2.6$ (pair of d, ${ }^{1} J\left({ }^{107} \mathrm{Ag}\right.$, $\left.\left.{ }^{31} \mathrm{P}\right)=543 \mathrm{~Hz},{ }^{1} J\left({ }^{109} \mathrm{Ag},{ }^{31} \mathrm{P}\right)=471 \mathrm{~Hz}\right)$. IR (Nujol): $\nu_{\max } 3389$ (m), 3079 (w), 1629 (s), 1615 (s), 1544 (s), 1480 (w), 1435 (m), 1412 (m), 1301 (m), $1194(\mathrm{~m}), 1174(\mathrm{~m}), 1095$ (s), 1067 (br s), $1050(\mathrm{w}), 1031(\mathrm{~m}), 914(\mathrm{~m}), 816(\mathrm{~m}), 748(\mathrm{~s}), 697$ (s), $623(\mathrm{~m})$, $529(\mathrm{~m}), 509(\mathrm{~s}), 492(\mathrm{~m}), 467(\mathrm{~m}) \mathrm{cm}^{-1}$. ESI+ MS: $m / z 961$ 
$\left(\left[\mathrm{Ag}(4)_{2}\right]^{+}\right), \quad 534\left([\mathrm{Ag}(4)]^{+}\right)$. Anal. Calc. for $\mathrm{C}_{48} \mathrm{H}_{44} \mathrm{AgClFe}_{2}-$ $\mathrm{N}_{2} \mathrm{O}_{6} \mathrm{P}_{2} \cdot \mathrm{CH}_{2} \mathrm{Cl}_{2}$ (1146.7): C 51.32, $\mathrm{H} 4.04, \mathrm{~N} 2.44 \%$. Found: C 50.90, H 3.75, N 2.13\%.

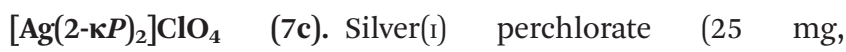
$0.12 \mathrm{mmol})$ and amide $2(107 \mathrm{mg}, 0.24 \mathrm{mmol})$ were reacted in benzene $(2 \mathrm{~mL})$ and dichloromethane $(4 \mathrm{~mL})$ for $4 \mathrm{~h}$ as described above. The solid product was filtered off, washed with diethyl ether and dried under vacuum. Yield of 7c: $84 \mathrm{mg}$ (62\%), yellow-brown solid.

${ }^{1} \mathrm{H}$ NMR (399.95 MHz, dmso-d ${ }_{6}$ ): $\delta 2.91$ (br s, $3 \mathrm{H}, \mathrm{NMe}$ ), 2.99 (br s, 3 H, NMe), 4.22 (br s, 2 H, fc), 4.32 (br s, 2 H, fc), 4.61 (vt, $J^{\prime}=1.9 \mathrm{~Hz}, 2 \mathrm{H}, \mathrm{fc}$ ), 4.65 (vt, $J^{\prime}=1.9 \mathrm{~Hz}, 2 \mathrm{H}, \mathrm{fc}$ ), 7.49-7.56 (m, $\left.10 \mathrm{H}, \mathrm{PPh}_{2}\right) .{ }^{31} \mathrm{P}\left\{{ }^{1} \mathrm{H}\right\}$ NMR $(161.90 \mathrm{MHz}$, dmso$\mathrm{d}_{6}$ ): $\delta 4.2$ (pair of concentric $\mathrm{d},{ }^{1} J\left({ }^{107} \mathrm{Ag},{ }^{31} \mathrm{P}\right)=770 \mathrm{~Hz}$, $\left.{ }^{1} J\left({ }^{109} \mathrm{Ag},{ }^{31} \mathrm{P}\right)=685 \mathrm{~Hz}\right)$. IR (Nujol): $\nu_{\max } 1557$ (s), $1492(\mathrm{~s})$, $1436(\mathrm{~m}), 1127$ (m), 1109 (s), 1097 (m), 1071 (w), 1050 (s), $824(\mathrm{w}), 758(\mathrm{~m}), 747(\mathrm{~m}), 695(\mathrm{~m}), 679(\mathrm{~s}), 623(\mathrm{~s}), 514(\mathrm{w})$, $503(\mathrm{w}), 490(\mathrm{~m}), 467(\mathrm{w}) \mathrm{cm}^{-1}$. ESI+ MS: $\mathrm{m} / z 989\left(\left[\mathrm{Ag}(2)_{2}\right]^{+}\right)$, $548\left([\mathrm{Ag}(2)]^{+}\right)$. Anal. Calc. for $\mathrm{C}_{50} \mathrm{H}_{48} \mathrm{AgClFe}_{2} \mathrm{~N}_{2} \mathrm{O}_{6} \mathrm{P}_{2} \cdot 1 / 2 \mathrm{CH}_{2} \mathrm{Cl}_{2}$ (1132.3): C 53.56, H 4.36, N 2.47\%. Found: C 53.30, H 4.15, $\mathrm{N} 2.35 \%$.

$\left[\mathrm{Ag}_{2}\left(\mathbf{C l O}_{4}\right)_{2}(\boldsymbol{\mu}-3)_{2}\right](\mathbf{7 d})$. Thioamide $3(50 \mathrm{mg}, 0.11 \mathrm{mmol})$ and $\mathrm{AgClO}_{4}(10 \mathrm{mg}, 0.048 \mathrm{mmol})$ were reacted in benzene $(2 \mathrm{~mL})$ and dichloromethane $(6 \mathrm{~mL})$ as described above. The solid product was filtered off, washed with pentane and dried under vacuum. Yield of 7 d: $52 \mathrm{mg}(81 \%)$, red solid. Crystals suitable for X-ray diffraction analysis were grown by the reactive diffusion approach as follows. A solution of ligand 3 (46 mg, $0.1 \mathrm{mmol}$ ) in dichloromethane $(2 \mathrm{~mL})$ was layered with pure solvent ( $1 \mathrm{~mL}$ of dichloromethane) and then with a solution of $\mathrm{AgClO}_{4}(10.5 \mathrm{mg}, 0.051 \mathrm{mmol})$ in benzene $(3 \mathrm{~mL})$. The mixture was allowed to stand undisturbed for several days during which time red crystals deposited in the phase boundary region. These crystals were directly used for the X-ray measurements. IR analysis of the isolated material confirmed it to be identical to the authentic (bulk) sample of $7 \mathbf{d}$.

${ }^{1} \mathrm{H}$ NMR (399.95 MHz, dmso-d $\mathrm{d}_{6}$ ): $\delta 3.39$ (s, $\left.3 \mathrm{H}, \mathrm{NMe}\right), 3.56$ (s, $3 \mathrm{H}, \mathrm{NMe}), 4.12$ (dt, $J=3.0,1.8 \mathrm{~Hz}, 2 \mathrm{H}, \mathrm{fc}$ ), 4.30 (vt, $J^{\prime}=$ $1.9 \mathrm{~Hz}, 2 \mathrm{H}, \mathrm{fc}$ ), 4.73 (vt, $J^{\prime}=1.8 \mathrm{~Hz}, 2 \mathrm{H}, \mathrm{fc}$ ), 5.06 (vt, $J^{\prime}=$ $1.9 \mathrm{~Hz}, 2 \mathrm{H}, \mathrm{fc}), 7.50-7.57\left(\mathrm{~m}, 10 \mathrm{H}, \mathrm{PPh}_{2}\right) .{ }^{31} \mathrm{P}\left\{{ }^{1} \mathrm{H}\right\} \mathrm{NMR}$ $\left(161.90 \mathrm{MHz}\right.$, dmso-d $\left.{ }_{6}\right): \delta-0.3$ (broad d, ${ }^{1} J\left({ }^{107 / 109} \mathrm{Ag},{ }^{31} \mathrm{P}\right)$ $\approx 510 \mathrm{~Hz}$ ). IR (Nujol): $\nu_{\max } 1551$ (s), $1436(\mathrm{~m}), 1280(\mathrm{~m}), 1144$ (m), 1108 (s), $1096(\mathrm{~s}), 1061$ (m), $1030(\mathrm{~m}), 979(\mathrm{~m}), 851(\mathrm{~m})$, $818(\mathrm{w}), 749(\mathrm{~m}), 695(\mathrm{~m}), 623(\mathrm{~m}), 507(\mathrm{~m}), 465(\mathrm{~m}) \mathrm{cm}^{-1}$. ESI+ MS: $m / z 564\left([\mathrm{Ag}(3)]^{+}\right), 597\left(\left[\mathrm{Ag}(3)\left(\mathrm{CH}_{3} \mathrm{OH}\right)\right]^{+}\right)$. Anal. Calc. for $\mathrm{C}_{50} \mathrm{H}_{48} \mathrm{Ag}_{2} \mathrm{Cl}_{2} \mathrm{Fe}_{2} \mathrm{~N}_{2} \mathrm{O}_{8} \mathrm{P}_{2} \mathrm{~S}_{2}$ (1329.3): C 45.17, $\mathrm{H} 3.64, \mathrm{~N} 2.11 \%$. Found: C 44.83, H 3.81, N 1.90\%.

\section{Synthesis of chloridogold(I) complexes}

[AuCl(5-кP)] (8a). Amide 5 (71 mg, $0.17 \mathrm{mmol})$ and chlorido (tetrahydrothiophene)gold(I) $(55 \mathrm{mg}, 0.17 \mathrm{mmol})$ were dissolved in dry dichloromethane $(2 \mathrm{~mL})$. The resulting solution was stirred at room temperature for $4 \mathrm{~h}$, whereupon it deposited a yellow solid. This solid was filtered off, washed with pentane and dried under vacuum to afford $\mathbf{8 a}$ as a yellow solid. Yield: $102 \mathrm{mg}$ (92\%).

${ }^{1} \mathrm{H}$ NMR (399.95 MHz, dmso-d $\mathrm{d}_{6}$ ): $\delta 4.28$ (vt, $J^{\prime}=1.9 \mathrm{~Hz}, 2 \mathrm{H}$, fc), $4.48(\mathrm{dt}, J=3.0,1.9 \mathrm{~Hz}, 2 \mathrm{H}, \mathrm{fc}), 4.59-4.61(\mathrm{~m}, 2 \mathrm{H}, \mathrm{fc}), 4.78$ (vt, $J^{\prime}=1.9 \mathrm{~Hz}, 2 \mathrm{H}, \mathrm{fc}$ ), 7.02 (br s, $1 \mathrm{H}, \mathrm{NH}$ ), 7.37 (br s, $1 \mathrm{H}$, $\mathrm{NH}), 7.54-7.64\left(\mathrm{~m}, 10 \mathrm{H}, \mathrm{PPh}_{2}\right) \cdot{ }^{31} \mathrm{P}\left\{{ }^{1} \mathrm{H}\right\}$ NMR $(161.90 \mathrm{MHz}$, dmso-d ${ }_{6}$ ): $\delta 28.7$ (s). IR (Nujol): $\nu_{\max } 3421$ (m), 1667 (s), $1612(\mathrm{~m}), 1432$ (m), 1349 (m), 1176 (m), 1099 (m), 1027 (m), $843(\mathrm{~m}), 822(\mathrm{~m}), 745(\mathrm{~m}), 688(\mathrm{~s}), 526(\mathrm{~m}), 511(\mathrm{~m}), 496(\mathrm{w})$, $477(\mathrm{~s}) \mathrm{cm}^{-1}$. ESI+ MS: $m / z 610\left([8 \mathbf{a}-\mathrm{Cl}]^{+}\right), 668\left([8 \mathbf{a}+\mathrm{Na}]^{+}\right)$, $684\left([8 \mathrm{a}+\mathrm{K}]^{+}\right)$. Anal. Calcd for $\mathrm{C}_{23} \mathrm{H}_{20} \mathrm{AuClFeNOP}$ (645.6): C 41.75, N 2.12, H 3.05\%. Found: C 41.56, N 1.93, H 2.96\%.

[AuCl(4-KP)] (8b). Amide $4(90 \mathrm{mg}, 0.22 \mathrm{mmol})$ and [AuCl(tht)] (68 mg, $0.21 \mathrm{mmol}$ ) were reacted in $2 \mathrm{~mL}$ of dichloromethane as described above to furnish $\mathbf{8 b}$ as a yellow powder. Yield: $126 \mathrm{mg}$ (91\%).

${ }^{1} \mathrm{H}$ NMR $\left(399.95 \mathrm{MHz}, \mathrm{CDCl}_{3}\right): \delta 2.93\left(\mathrm{~d},{ }^{3} J_{\mathrm{HH}}=4.8 \mathrm{~Hz}, 3 \mathrm{H}\right.$, NMe), 4.19 (vt, $\left.J^{\prime}=1.8 \mathrm{~Hz}, 2 \mathrm{H}, \mathrm{fc}\right), 4.23(\mathrm{dt}, J=2.9,1.9 \mathrm{~Hz}, 2 \mathrm{H}$, fc), $4.68-4.70(\mathrm{~m}, 2 \mathrm{H}, \mathrm{fc}), 4.87$ (vt, $\left.J^{\prime}=1.9 \mathrm{~Hz}, 2 \mathrm{H}, \mathrm{fc}\right), 6.07$ (q, $\left.{ }^{3} J_{\mathrm{HH}}=4.8 \mathrm{~Hz}, 1 \mathrm{H}, \mathrm{NH}\right), 7.44-7.61\left(\mathrm{~m}, 10 \mathrm{H}, \mathrm{PPh}_{2}\right) .{ }^{31} \mathrm{P}\left\{{ }^{1} \mathrm{H}\right\}$ NMR (161.90 MHz, $\mathrm{CDCl}_{3}$ ): $\delta 28.8$ (s). IR (Nujol): $\nu_{\max } 3369$ (m), $1628(\mathrm{~s}), 1544(\mathrm{~m}), 1440(\mathrm{~m}), 1298(\mathrm{~m}), 1173(\mathrm{~m}), 1103(\mathrm{w})$, $1029(\mathrm{~m}), 1000(\mathrm{w}), 842(\mathrm{~m}), 743(\mathrm{~m}), 691(\mathrm{~m}), 628(\mathrm{w}), 555(\mathrm{w})$, $529(\mathrm{w}), 515(\mathrm{w}), 494(\mathrm{w}), 480(\mathrm{w}) \mathrm{cm}^{-1}$. ESI+ MS: $\mathrm{m} / z 624([\mathbf{8 b}$ $\left.-\mathrm{Cl}]^{+}\right), 680\left([8 \mathbf{b}+\mathrm{Na}]^{+}\right), 698\left([8 \mathbf{b}+\mathrm{K}]^{+}\right)$. Anal. Calcd for $\mathrm{C}_{24} \mathrm{H}_{22} \mathrm{AuClFeNOP} \cdot 1 / 2 \mathrm{CHCl}_{3}$ (719.3): C 40.90, N 1.95, H 3.15\%. Found C 41.04, N 1.79, H 3.09\% (analytical sample crystallised from chloroform/pentane).

[AuCl(2-kP)] (8c). Amide $2(55 \mathrm{mg}, 0.12 \mathrm{mmol})$ and [AuCl(tht)] (40 mg, $0.12 \mathrm{mmol}$ ) were dissolved in dichloromethane $(2 \mathrm{~mL})$. After stirring for $4 \mathrm{~h}$, the solution was precipitated with diethyl ether and the product was filtered off and dried under vacuum. Yield of 8c: $61 \mathrm{mg}$ (73\%), yellow powder.

${ }^{1} \mathrm{H}$ NMR (399.95 MHz, dmso-d ${ }_{6}$ ): $\delta 2.85$ (s, $3 \mathrm{H}, \mathrm{NMe}$ ), 3.00 (s, $3 \mathrm{H}, \mathrm{NMe}$ ), 4.30 (vt, $J^{\prime}=1.9 \mathrm{~Hz}, 2 \mathrm{H}, \mathrm{fc}$ ), 4.43 (dt, $J=3.0$, $1.8 \mathrm{~Hz}, 2 \mathrm{H}, \mathrm{fc}), 4.61$ (vt, $\left.J^{\prime}=1.8 \mathrm{~Hz}, 2 \mathrm{H}, \mathrm{fc}\right), 4.73-4.76(\mathrm{~m}, 2 \mathrm{H}$, fc), 7.54-7.65 (m, $\left.10 \mathrm{H}, \mathrm{PPh}_{2}\right) .{ }^{31} \mathrm{P}\left\{{ }^{1} \mathrm{H}\right\}$ NMR $(161.90 \mathrm{MHz}$, dmso-d ${ }_{6}$ ): $\delta 28.9$ (s). IR (Nujol): $\nu_{\max } 3103(\mathrm{~m}), 1622(\mathrm{~s}), 1585$ (m), $1499(\mathrm{~m}), 1439$ (s), 1393 (m), 1308 (m), 1265 (m), 1225 (m), $1180(\mathrm{~m}), 1173(\mathrm{~m}), 1107(\mathrm{~s}), 1039(\mathrm{~m}), 1032(\mathrm{~m}), 840(\mathrm{~m})$, $821(\mathrm{~m}), 758(\mathrm{~s}), 752(\mathrm{~s}), 704(\mathrm{~s}), 558(\mathrm{~m}), 535(\mathrm{~m}), 526(\mathrm{~s})$, $504(\mathrm{~s}), 490(\mathrm{~s}), 474(\mathrm{~m}) \mathrm{cm}^{-1}$. ESI+ MS: $m / z 638\left(\left[8 \mathrm{c}-\mathrm{Cl}^{+}\right)\right.$, $696\left([8 \mathrm{c}+\mathrm{Na}]^{+}\right), 712\left([8 \mathrm{c}+\mathrm{K}]^{+}\right)$. Anal. Calcd for $\mathrm{C}_{25} \mathrm{H}_{24^{-}}$ AuClFeNOP (673.7): C 44.57, N 2.08, H 3.59\%. Found: C 44.22, $\mathrm{N} 2.01, \mathrm{H} 3.50 \%$.

[AuCl(3-KP)] (8d). Ligand $3(38 \mathrm{mg}, 0.083 \mathrm{mmol})$ and [AuCl(tht)] (26 mg, $0.081 \mathrm{mmol})$ were reacted in $\mathrm{CH}_{2} \mathrm{Cl}_{2}(2 \mathrm{~mL})$ overnight. The separated solid was filtered off, washed with diethyl ether and dried under vacuum to afford $\mathbf{8 d}$ as a dark orange solid. Yield: $36 \mathrm{mg}$ (64\%).

${ }^{1} \mathrm{H}$ NMR (399.95 MHz, dmso-d ${ }_{6}$ ): $\delta 3.27$ (s, $3 \mathrm{H}, \mathrm{NMe}$ ), 3.29 (s, $3 \mathrm{H}, \mathrm{NMe}$ ), 4.34 (vt, $J^{\prime}=1.9 \mathrm{~Hz}, 2 \mathrm{H}, \mathrm{fc}$ ), 4.35 (dt, $J=3.0$, $1.8 \mathrm{~Hz}, 2 \mathrm{H}, \mathrm{fc}), 4.73\left(\mathrm{vt}, J^{\prime}=1.9 \mathrm{~Hz}, 2 \mathrm{H}, \mathrm{fc}\right), 4.76-4.79(\mathrm{~m}, 2 \mathrm{H}$, fc), 7.54-7.65 (m, $\left.10 \mathrm{H}, \mathrm{PPh}_{2}\right) \cdot{ }^{31} \mathrm{P}\left\{{ }^{1} \mathrm{H}\right\}$ NMR $(161.90 \mathrm{MHz}$, dmso-d $_{6}$ ): $\delta 28.7$ (s). IR (Nujol): $\nu_{\max } 1712$ (w), 1512 (s), 1435 (m), 1309 (m), 1274 (m) 1174 (m), 1138 (m), 1101 (s), 
$1062(\mathrm{w}), 1034(\mathrm{w}), 1025(\mathrm{w}), 989(\mathrm{w}), 973(\mathrm{w}), 838(\mathrm{~m}), 824(\mathrm{~m})$, $814(\mathrm{w}), 764(\mathrm{w}), 749(\mathrm{~m}), 695(\mathrm{~s}), 556(\mathrm{~m}), 530(\mathrm{~m}), 509(\mathrm{~s})$, $498(\mathrm{w}), 477(\mathrm{~m}) \mathrm{cm}^{-1}$. ESI+ MS: $m / z 654\left([8 d-\mathrm{Cl}]^{+}\right.$. Anal. calcd for $\mathrm{C}_{25} \mathrm{H}_{24} \mathrm{AuClFeNPS}$ (689.8): C 43.53, N 2.03, H 3.51\%. Found: C 43.88, N 1.87, H 3.45\%.

\section{X-ray crystallography}

Crystallisation conditions are described in the ESI. $\uparrow$ Full set diffraction data $\left( \pm h \pm k \pm l, \theta_{\max }=26.0-27.5^{\circ}\right.$, completeness $\geq 99.3 \%$ ) were collected with a Nonius Kappa CCD diffractometer equipped with an Apex II image plate detector and Cryostream Cooler (Oxford Cryosystems) using graphite monochromated Mo $K \alpha$ radiation $(\lambda=0.71073 \AA$ ). The data were analysed and corrected for absorption by methods included in the diffractometer software. Details on the data collection, structure solution and refinement are available in the ESI (Table S1†), which also contains conventional displacement ellipsoid plots.

All structures were solved by direct methods (SHELXS97 ${ }^{42}$ ) and refined by full-matrix least-squares based on $F^{2}$ $\left(\mathrm{SHELXL97}^{42}\right)$. The non-hydrogen atoms were refined with anisotropic displacement parameters. The amide hydrogen atoms (NH; if present) were located on the difference electron density maps and refined as riding atoms with $U_{\text {iso }}(\mathrm{H})$ set to a $1.2 U_{\mathrm{eq}}(\mathrm{N})$. Hydrogens residing on the carbon atoms were included in their calculated positions and refined similarly with $U_{\text {iso }}(\mathrm{H})=1.5 U_{\text {eq }}(\mathrm{C})$ for the methyl groups and $1.2 U_{\text {eq }}(\mathrm{C})$ for all other $\mathrm{CH}_{n}$ moieties. Particular details of the structure refinement are as follows.

Compound $\mathbf{4 S}$ crystallises in the chiral $P c$ space group with two molecules per asymmetric unit. However, all atoms except for the amide moiety in these two independent molecules match each other because of an inversion centre from the space group $P 2_{1} / c$ (the maximum distance of the overlapping atoms in the phosphinoferrocenyl units is $0.53 \AA$ ). Such a virtually higher symmetry results in large correlations during the refinement and, therefore, restrictions to anisotropic displacement parameters had to be applied to several atoms.

Parts of some structures $\left(7 \mathbf{b} \cdot \mathrm{CHCl}_{3}\right.$ : the solvent and the perchlorate anion; $\mathbf{6 b} \cdot 1 / 4 \mathrm{CHCl}_{3}$ and $\mathbf{6} \mathbf{a}^{\prime} \cdot \mathrm{CHCl}_{3}$ : one of the phosphorus-bound phenyl rings and the $\mathrm{BF}_{4}{ }^{-}$anion) are disordered and were refined over two positions (with isotropic displacement parameters, if necessary). Moreover, the solvating molecules in the structures of $\mathbf{6 b} \cdot 1 / 4 \mathrm{CHCl}_{3}$ and $\mathbf{6} \mathbf{a}^{\prime} \cdot \mathrm{CHCl}_{3}$ are severely disordered in structural voids and were modelled by PLATON/SQUEEZE. ${ }^{43}$

All geometric calculations were performed and the diagrams were obtained with the PLATON program. ${ }^{44}$ All numerical values were rounded with respect to their estimated deviations (ESDs) given to one decimal place. Parameters relating to atoms in constrained positions (hydrogens) are given without ESDs.

\section{DFT computations}

Calculations were performed using the density-functional theory (DFT) with Becke's three-parameter functional ${ }^{45}$ employing the non-local Lee-Yang-Parr correlation functional $(\mathrm{B} 3 \mathrm{LYP})^{46}$ and the $6-31 \mathrm{G}^{*}$ basis set for $\mathrm{FcC}(\mathrm{E}) \mathrm{NH}_{2}$ and $6-311 G^{* *}$ for 2 and 3 with an analytically constructed energy gradient as implemented in the Gaussian 09 program package. ${ }^{47}$ Geometry optimisations were started from the experimentally determined solid-state structures of 2, 3 and $\mathrm{FcCONH}_{2} \cdot{ }^{27 b}$ The stationary points of the potential energy surface (PES) were located and harmonic vibrational analysis was performed using the analytically calculated force-constant matrix. For the case of $\mathrm{FcC}(\mathrm{E}) \mathrm{NH}_{2}(\mathrm{E}=\mathrm{O}, \mathrm{S})$, relaxed PES scan using $\psi$ as a single variable was performed, starting from the respective stationary points.

\section{Electrochemistry}

Electrochemical measurements were carried out with a $\mu$ AUTOLAB III instrument (Eco Chemie) at room temperature $\left(23^{\circ} \mathrm{C}\right)$ using a standard three-electrode cell (Metrohm) equipped with a glassy carbon disc working electrode ( $2 \mathrm{~mm}$ diameter), platinum sheet auxiliary electrode, and a double-junction $\mathrm{Ag} / \mathrm{AgCl}$ (3 $\mathrm{M} \mathrm{KCl)} \mathrm{reference} \mathrm{electrode.} \mathrm{The} \mathrm{samples} \mathrm{were} \mathrm{dissolved} \mathrm{in}$ anhydrous 1,2-dichloroethane (Sigma-Aldrich; absolute) to give a solution containing $1 \times 10^{-3} \mathrm{M}$ of the analysed compound and $0.1 \mathrm{M} \mathrm{Bu}_{4} \mathrm{~N}\left[\mathrm{PF}_{6}\right]$ (Fluka, p. a. for electrochemistry). The solutions were deaerated by bubbling with argon and then kept under an argon blanket during the measurement. The redox potentials are given relative to the ferrocene/ferrocenium reference.

\section{Acknowledgements}

This research was supported through the grants from the Czech Science Foundation (project no. 13-08890S) and the Grant Agency of Charles University in Prague (project no. 643012).

\section{Notes and references}

1 P. Štěpnička, Chem. Soc. Rev., 2012, 41, 4273.

2 For recent examples, see: (a) N. Nasser, P. D. Boyle and R. J. Puddephatt, Organometallics, 2013, 32, 5504; (b) N. Nasser and R. J. Puddephatt, Inorg. Chim. Acta, 2014, 409, 238; (c) E. C. Constable, N. Hostettler, C. E. Housecroft, N. S. Murray, J. Schönle, U. Soydaner, R. M. Walliser and J. A. Zampese, Dalton Trans., 2013, 42, 4970; (d) N. Ye and W.-M. Dai, Eur. J. Org. Chem., 2013, 831; (e) I. Philipova, G. Stavrakov and V. Dimitrov, Tetrahedron: Asymmetry, 2012, 23, 927.

3 For recent examples, see: (a) J. Schulz, I. Císařová and P. Štěpnička, Organometallics, 2012, 31, 729; (b) J. Tauchman, B. Therrien, G. Süss-Fink and P. Štěpnička, Organometallics, 2012, 31, 3985; (c) J. Schulz, I. Císařová and P. Štěpnička, Eur. J. Inorg. Chem., 2012, 5000; (d) J. Tauchman, I. Císařová and P. Štěpnička, Dalton Trans., 2011, 40, 11748; (e) P. Štěpnička, B. Schneiderová, 
J. Schulz and I. Císařová, Organometallics, 2013, 32, 5754; (f) J. Schulz, J. Tauchman, I. Císařová, T. Riedel, P. J. Dyson and P. Štěpnička, J. Organomet. Chem., 2014, 751, 604; (g) P. Štěpnička, M. Verníček, J. Schulz and I. Císařová, J. Organomet. Chem., 2014, 755, 41; $(h)$ M. Semler, J. Čejka and P. Štěpnička, Catal. Today, 2014, 227, 207; (i) H. Solařová, I. Císařová and P. Štěpnička, Organometallics, 2014, 33, 4131; (j) J. Tauchman, I. Císařová and P. Štěpnička, Dalton Trans., 2014, 43, 1599.

4 (a) A. El-Faham and F. Albericio, Chem. Rev., 2011, 111, 6557; (b) E. Valeur and M. Bradley, Chem. Soc. Rev., 2009, 38, 606 .

5 J. Podlaha, P. Štěpnička, J. Ludvík and I. Císařová, Organometallics, 1996, 15, 543.

6 This method represents a versatile route to phosphinoferrocenes functionalised in position $1^{\prime}$ of the ferrocene unit. For examples, see: (a) I. R. Butler and R. L. Davies, Synthesis, 1996, 1350; (b) P. Šťpnička, in Ferrocenes: Ligands, Materials and Biomolecules, Wiley, Chichester, 2008, ch. 5, pp. 177-204.

7 P. Štěpnička, H. Solařová, M. Lamač and I. Císařová, J. Organomet. Chem., 2010, 695, 2423.

8 For representative examples of (thio)amide synthesis from organolithium reagents and (thio)carbamoyl halides, see: (a) E. G. Doadt and V. Snieckus, Tetrahedron Lett., 1985, 26, 1149; (b) M. P. Sibi, S. Chattopadhyay, J. W. Dankwardt and V. Snieckus, J. Am. Chem. Soc., 1985, 107, 6312; (c) E. J. Bures and B. A. Keay, Tetrahedron Lett., 1988, 29, 1247; (d) R. J. Mills, N. J. Taylor and V. Snieckus, J. Org. Chem., 1989, 54, 4372; (e) D. L. Comins and H. Hong, J. Am. Chem. Soc., 1991, 113, 6672; $(f)$ P. Gros, Y. Fort, G. Queguiner and P. Caubere, Tetrahedron Lett., 1995, 36, 4791; (g) J. Clayden, N. Westlund and F. X. Wilson, Tetrahedron Lett., 1999, 40, 7883; (h) F. Wudl, S. D. Cox and D. E. Wellman, Mol. Cryst. Liq. Cryst., 1985, 125, 181.

9 For examples of the reactions of lithioferrocenes with thiocarbamoyl chlorides, see: (a) K. Hamamura, M. Kita, M. Nonoyama and J. Fujita, J. Organomet. Chem., 1993, 463, 169; (b) S. Jautze, P. Seiler and R. Peters, Angew. Chem., Int. Ed., 2007, 46, 1260; (c) S. Jautze, P. Seiler and R. Peters, Chem. - Eur. J., 2008, 14, 1430; (d) T. Hellmuth, S. Rieckhoff, M. Weiss, K. Dorst, W. Frey and R. Peters, ACS Catal., 2014, 4, 1850 N.B. The amidation of ferrocene with carbamoyl chlorides has been typically achieved through Friedel-Crafts reactions: (e) W. F. Little and R. Eisenthal, J. Am. Chem. Soc., 1960, 82, 1577; (f) J. Hu, L. J. Barbour and G. W. Gokel, New J. Chem., 2004, 28, 907.

10 Thioamides are typically synthesised through thionation of amides with Lawesson's reagent or $\mathrm{P}_{2} \mathrm{~S}_{5}$ which, however, convert phosphines to phosphine sulfides: (a) M. Jesberger, T. P. Davis and L. Barner, Synthesis, 2003, 1929; (b) T. Ozturk, E. Ertas and O. Mert, Chem. Rev., 2010, 110, 3419; (c) A. B. Charette and M. Grenon, J. Org. Chem., 2003, 68, 5792 and references cited therein.

11 This contrasts with the attention dedicated to simple and multi-donor (non-phosphine) thioamide donors. For selected examples, see: E. S. Raper, Coord. Chem. Rev., 1994, 129, 91; W. Zhang and M. Shi, Synlett, 2007, 19; K. Belhamel, T. K. D. Nguyen, M. Benamor and R. Ludwig, Eur. J. Inorg. Chem., 2003, 4110; M. A. Hossain, S. Lucarini, D. Powell and K. Bowman-James, Inorg. Chem., 2004, 43, 7275; R. A. Begum, D. Powell and K. Bowman-James, Inorg. Chem., 2006, 45, 964; N. K. Singh, M. Singh, P. Tripathi, A. K. Srivastava and R. J. Butcher, Polyhedron, 2007, 27, 375; K. Ahlford, M. Livendahl and H. Adolfsson, Tetrahedron Lett., 2009, 50, 6321; J. Kulesza, M. Guzinski, V. Hubscher-Bruder, F. Arnaud-Neu and M. Bocheńska, Polyhedron, 2011, 30, 98; T. Teratani, T. Koizumi, T. Yamamoto, K. Tanaka and T. Kanbara, Dalton Trans., 2011, 40, 8879 and references therein; T. Suzuki, Y. Kajita and H. Masuda, Dalton Trans., 2014, 43, 9732.

12 P.-H. Leung, Y. Qin, G. He, K. F. Mok and J. J. Vittal, J. Chem. Soc., Dalton Trans., 2001, 309.

13 For representative examples, see: (a) K. Issleib and G. Harzfeld, Chem. Ber., 1964, 97, 3430; (b) K. Issleib and G. Harzfeld, Z. Anorg. Allg. Chem., 1967, 351, 18; (c) E. W. Abel and I. H. Sabherwal, J. Chem. Soc. A, 1968, 1105; (d) A. W. Gal, J. W. Gosselink and F. A. Vollenbroek, J. Organomet. Chem., 1977, 142, 357; (e) H. P. M. M. Ambrosius, F. A. Cotton, L. R. Falvello, H. T. J. M. Hintzen, T. J. Melton, W. Schwotzer, M. Tomas and J. G. M. Van der Linden, Inorg. Chem., 1984, 23, 1611; (f) U. Kunze, H. Jawad, R. Burghardt, R. Tittmann and V. Kruppa, J. Organomet. Chem., 1986, 302, C30 and previous articles in this series; $(g)$ A. Gutierrez-Alonso, L. Ballester-Reventos, V. Perez-Garcia and C. Ruiz-Valero, Polyhedron, 1990, 9, 2163; (h) D. Clajus, R. Kramolowsky, G. Siasios and E. R. T. Tiekink, Inorg. Chim. Acta, 1998, 281, 64; (i) O. Crespo, E. J. Fernandez, P. G. Jones, A. Laguna, J. M. Lopez de Luzuriaga, M. Monge, M. E. Olmos and J. Perez, Dalton Trans., 2003, 1076; (j) A. C. Behrle and J. A. R. Schmidt, Organometallics, 2013, 32, 1141.

14 (a) A. Bader and E. Lindner, Coord. Chem. Rev., 1991, 108, 27; (b) C. S. Slone, D. A. Weinberger and C. A. Mirkin, Prog. Inorg. Chem., 1999, 48, 233; (c) P. Braunstein and F. Naud, Angew. Chem., Int. Ed., 2001, 40, 680.

15 P. Štěpnička, J. Schulz, I. Císařová and K. Fejfarová, Collect. Czech. Chem. Commun., 2007, 72, 453.

16 The $\mathrm{C}=\mathrm{S}$ stretching band is probably obscured by Nujol. See, for instance, the data for $\mathrm{PhC}(\mathrm{S}) \mathrm{NC}_{5} \mathrm{H}_{10}$ : K. A. Jensen and P. H. Nielsen, Acta Chem. Scand., 1966, 20, 597.

17 D. Plażuk, J. Zakrzewski, A. Rybarczyk-Pirek and S. Domagała, J. Organomet. Chem., 2005, 690, 4302.

18 P. Štěpnička and I. Císařová, J. Organomet. Chem., 2006, 691, 2863.

19 (a) J. Kühnert, M. Dušek, J. Demel, H. Lang and P. Štěpnička, Dalton Trans., 2007, 2802; (b) J. Kühnert, I. Císařová, M. Lamač and P. Štěpnička, Dalton Trans., 2008, 2454; (c) J. Schulz, I. Císařová and P. Štěpnička, J. Organomet. Chem., 2009, 694, 2519; (d) J. Tauchman, I. Císařová and P. Štepnička, Organometallics, 2009, 28, 3288 and also ref. $3 a, c$ and $e$. 
20 A $\mathrm{C} 7-\mathrm{H} 7 \cdots \mathrm{S}=\mathrm{C}$ interaction between molecules related by elemental translation along the crystallographic $a$-axis can be found in the structure of 30: C7 $\cdots \mathrm{S}=3.689(2) \AA$, angle at $\mathrm{H} 7=151^{\circ}$.

21 The difference in electronegativity is considerably higher in the $\mathrm{P} / \mathrm{O}$ pair than in the $\mathrm{C} / \mathrm{O}$ pair.

22 Change in the mutual orientation of the cyclopentadienyl ring (i.e., conformation of the 1,1'-disubstited ferrocene scaffold) results in changes in the $\mathrm{C}$ (ring1)-Fe-C(ring2) angles, which is also the present case. This concerns mainly amide 2; the maximum difference in interatomic angles for 3 is only $5^{\circ}$.

23 (a) D. R. Scott and R. S. Becker, J. Chem. Phys., 1961, 35, 516 (erratum: D. R. Scott and R. S. Becker, J. Chem. Phys., 1961, 35, 2246

(b) U. Salzner, J. Chem. Theor. Comput., 2013, 9, 4064.

24 The position of the absorption band is of course reflected in the colours of the compounds. Whereas amide 2 is orange (orange brown as a bulk solid), thioamide 3 is intensely red-orange (red in the solid state).

25 C. Hansch, A. Leo and R. W. Taft, Chem. Rev., 1991, 91, 165.

26 J. A. S. Howell, P. C. Yates, N. Fey, P. McArdle, D. Cunningham, S. Parsons and D. W. H. Rankin, Organometallics, 2002, 21, 5272 (Note: the value was calculated from the data deposited in CSD).

27 In the case of primary amides, $\mathrm{FcC}(\mathrm{E}) \mathrm{NH}_{2}$, the comparison is not possible because the individual molecules are involved in hydrogen-bonding interactions that influence molecular conformations. For instance, the $\psi$ angles determined from the crystal structure data of $\mathrm{FcCONH}_{2}$ are $-13.9^{\circ},-9.7(2)^{\circ}$ and $-8.4(2){ }^{\circ}$ for different polymorphs: (a) D. Salazar-Mendoza, S. A. Baudron, M. W. Hosseini, N. Kyritsakas and A. De Cian, Dalton Trans., 2007, 565 (Note: the first value was calculated from the data deposited with CCDC); (b) P. Štěpnička, I. Císařová, D. Nižňanský and S. Bakardjieva, Polyhedron, 2010, 29, 134. The corresponding thioamide $\mathrm{FcCSNH}_{2}$ shows a lower tilting in the solid state $\left(\psi \approx-3.7^{\circ}\right.$; ref. 17 , Note: the value was calculated from the data deposited with CCDC).

28 K. Nakamoto, in Infrared and Raman Spectra of Inorganic and Coordination Compounds, Wiley, New York, 5th edn, 1997, Part A: Theory and Applications in Inorganic Chemistry, ch. II-6, pp. 189-201, and Part B: Applications in Coordination, Organometallic and Bioinorganic Chemistry, ch. III-12, pp. 82-83.

29 The $\mathrm{M}-\mathrm{P}$ bonds between the soft phosphine donor group and the soft metal centre can be expected to be stronger than the M-O bonds involving the amide moiety.

30 R. G. Parr and R. G. Pearson, J. Am. Chem. Soc., 1983, 105, 7512.

31 J. Tauchman, I. Císařová and P. Štěpnička, Eur. J. Org. Chem., 2010, 4276.

32 A. Bondi, J. Phys. Chem., 1964, 68, 441.
33 Cambridge Structural Database version 5.35 of November 2013 with updates from November 2013, February 2014 and May 2014.

34 C. Pariya, F. R. Fronzek and A. W. Maverick, Inorg. Chem., 2011, 50, 2748.

35 C. Paryia, C. R. Sparrow, C.-K. Back, G. Sandí, F. R. Fronczek and A. W. Maverick, Angew. Chem., Int. Ed., 2007, 46, 6305.

36 The molecules differ by the overall conformation, mainly the phenyl rings (see an overlap in the ESI $\dagger$ ).

37 K. Rössler, T. Rüffer, B. Walfort, R. Packheiser, R. Holze, M. Zharnikov and H. Lang, J. Organomet. Chem., 2007, 692, 1530 .

38 (a) J. E. Aguado, S. Canales, M. C. Gimeno, P. G. Jones, A. Laguna and M. D. Villacampa, Dalton Trans., 2005, 3005; (b) J. Kühnert, P. Ecorchard and H. Lang, Eur. J. Inorg. Chem., 2008, 5125; (c) A. Hildebrandt, N. Wetzold, P. Ecorchard, B. Walfort, T. Rüffer and H. Lang, Eur. J. Inorg. Chem., 2010, 3615; (d) U. Siemeling, T. Klemann, C. Bruhn, J. Schulz and P. Štěpnička, Z. Anorg. Allg. Chem., 2011, 637, 1824; (e) P. Štěpnička, M. Zábranský and I. Císařová, ChemistryOpen, 2012, 1, 71.

39 H. Schmidbaur and A. Schier, Chem. Soc. Rev., 2012, 41, 370 and references cited therein.

40 I. R. Butler and R. L. Davies, Synthesis, 1996, 1350.

41 R. Uson, A. Laguna and M. Laguna, Inorg. Synth., 1989, 26, 85.

42 G. M. Sheldrick, Acta Crystallogr., Sect. A: Found. Crystallogr., 2008, 64, 112.

43 P. van der Sluis and A. L. Spek, Acta Crystallogr., Sect. A: Found. Crystallogr., 1990, 46, 194.

44 A. L. Spek, J. Appl. Crystallogr., 2003, 36, 7.

45 A. D. Becke, J. Chem. Phys., 1993, 98, 5648.

46 C. Lee, W. Yang and R. G. Parr, Phys. Rev. B: Condens. Matter, 1988, 37, 785.

47 M. J. Frisch, G. W. Trucks, H. B. Schlegel, G. E. Scuseria, M. A. Robb, J. R. Cheeseman, G. Scalmani, V. Barone, B. Mennucci, G. A. Petersson, H. Nakatsuji, M. Caricato, X. Li, H. P. Hratchian, A. F. Izmaylov, J. Bloino, G. Zheng, J. L. Sonnenberg, M. Hada, M. Ehara, K. Toyota, R. Fukuda, J. Hasegawa, M. Ishida, T. Nakajima, Y. Honda, O. Kitao, H. Nakai, T. Vreven, J. A. Montgomery Jr., J. E. Peralta, F. Ogliaro, M. Bearpark, J. J. Heyd, E. Brothers, K. N. Kudin, V. N. Staroverov, T. Keith, R. Kobayashi, J. Normand, K. Raghavachari, A. Rendell, J. C. Burant, S. S. Iyengar, J. Tomasi, M. Cossi, N. Rega, J. M. Millam, M. Klene, J. E. Knox, J. B. Cross, V. Bakken, C. Adamo, J. Jaramillo, R. Gomperts, R. E. Stratmann, O. Yazyev, A. J. Austin, R. Cammi, C. Pomelli, J. W. Ochterski, R. L. Martin, K. Morokuma, V. G. Zakrzewski, G. A. Voth, P. Salvador, J. J. Dannenberg, S. Dapprich, A. D. Daniels, O. Farkas, J. B. Foresman, J. V. Ortiz, J. Cioslowski and D. J. Fox, Gaussian 09, Revision C.01, Gaussian, Inc, Wallingford CT, 2010. 